Research Article

\title{
Flexural Response of Steel-Concrete Composite Truss Beams
}

\author{
Lisheng Luo $\mathbb{D}^{1}$ and Xiaofeng Zhang ${ }^{2}$ \\ ${ }^{1}$ College of Civil Engineering and Architecture, Hainan University, Haikou 570228, China \\ ${ }^{2}$ College of Materials Science and Engineering, Nanjing Forestry University, Nanjing 210037, China \\ Correspondence should be addressed to Lisheng Luo; luolisheng2015@hainanu.edu.cn
}

Received 27 March 2019; Revised 10 May 2019; Accepted 27 May 2019; Published 12 June 2019

Academic Editor: Farhad Aslani

Copyright (c) 2019 Lisheng Luo and Xiaofeng Zhang. This is an open access article distributed under the Creative Commons Attribution License, which permits unrestricted use, distribution, and reproduction in any medium, provided the original work is properly cited.

\begin{abstract}
This paper presents an experimental and analytical study on the flexural response of a steel-concrete composite truss beam. This integrated unit consists of a triangular steel truss, a concrete slab on it, and stud connectors. Three simply supported composite trusses with different configurations of shear connection $(\eta)$ were evaluated via three-point bending tests. The effects of the shear connectors' configuration on the flexural response (i.e., load-deflection, load-slippage, and load-strain curves) of the composite trusses were examined. The commercial finite-element (FE) software ANSYS was employed to conduct numerical simulations. An FE model was developed for the composite truss and was validated using experimental results. A parametric study was performed to investigate the effect of the shear connectors' configuration on the flexural response of the composite trusses. If $\eta<1$, the bending capacity increased with $\eta$. In contrast, if $\eta \geq 1$, the effect of $\eta$ on the bending capacity was negligible. Finally, a design method based on the degree of the shear connection was proposed to predict the ultimate capacity of the composite truss, and the predictions agreed well with the experimental results.
\end{abstract}

\section{Introduction}

Steel-concrete composite structural members are formed by bonding a steel component to a concrete component, so that the two components function as an integrated unit [1]. Composite structures can efficiently utilise the properties of the constituting materials to achieve material saving and cost efficiency. Composite members have been extensively applied in civil engineering, e.g., composite floors [2], composite columns [3, 4], and composite beams [5]. Among these members, the composite beam, which consists of a steel beam on which a reinforced concrete slab is cast with shear connectors, is the most widely used, because the properties of both materials are fully utilised (i.e., steel is strong in tension and concrete is strong in compression). To ensure composite action, shear connectors are commonly employed at the steel-concrete interface for resisting slippage and separation between the concrete slab and steel beam [1].

There are many types of mechanical shear connectors with various shapes, sizes, and methods of attachment, such as studs, bolts, channels, and angles. The stud connector is probably the most commonly used connector for steelconcrete composite beams [1]. To investigate the strength and load-slip behaviour of the stud shear connection, push tests have been widely conducted [6-8]. The failure modes of the stud connection mainly include failure at the shank of the stud, fracture in the welding zone, and concrete crushing [9]. The shear capacity of the stud generally depends on the diameter of the stud, strength of the steel used for the stud, and material properties of the concrete (i.e., strength and elastic modulus). Many calculation formulas have been proposed by researchers for estimating the strength and load-slip relationship of stud connections $[9,10]$. Current standards use similar formulas to estimate the shear capacity of stud connectors $\left(F_{\mathrm{u} 0}\right)$. Taking the standard GB 50017 [11] as an example and ignoring partial factors, we have

$$
F_{\mathrm{u} 0}=\min \left(0.43 A_{\mathrm{s}} \sqrt{E_{\mathrm{c}} f_{\mathrm{c}}}, 0.7 A_{\mathrm{s}} f_{\mathrm{u}}\right),
$$

where $A_{\mathrm{s}}$ is the cross-sectional area of the stud, $E_{\mathrm{c}}$ is the elastic modulus of concrete, $f_{c}$ is the strength of concrete, 
and $f_{\mathrm{u}}$ is the ultimate strength of stud connectors. The US and Europe standards adopt different coefficients to replace 0.43 and 0.7 in equation (1), 0.5 and 0.75 , respectively, in AISC [12], and 0.37 and 0.8, respectively, in EN1994.1.1 [13].

Studies on steel-concrete composite plane truss beams (also called "open-web composite steel joists") began in the 1960s, and these beams have been successfully applied in engineering projects, such as Reed Arena in the US and 1000 De La Gauchetiere Buildings in Canada [14]. Composite trusses are capable of achieving a large span with low cost, providing routes for ventilation and electrical lines and reducing the overall floor-to-floor height [14]. Robinson and Fahmy [15] experimentally investigated a composite joist with a partial shear connection. The joist failed via the buckling of the top chord in compression prior to full yielding of the bottom chord, and a design method was proposed for the composite joist with a partial shear connection. Two full-scale composite trusses were tested under bending by Brattland and Kennedy [16], which failed via shear-connector failure, followed by the overloading of the top chords. Muhammad [17] tested two composite trusses and adopted puddle welding or small screws as shear connectors. The composite truss with the puddle-welding connector exhibited better composite action, with a significantly higher flexural capacity and failed via the overall buckling of the top chords, while shear-bond failure was observed for the other specimen. Lopez [18] performed an in situ study on a composite truss floor system, and the buckling of diagonals near the support, which experienced strong axial forces, was identified as the major failure mode. A parametric study on a composite truss was conducted by Bouchair et al. [19], revealing that the top chord does not significantly affect the bending capacity of composite trusses. According to previous studies, the failure modes of composite trusses vary greatly, e.g., shear connectors' failure, buckling of the top chords, buckling of the diagonals, and fracture of the bottom chords. The complexity of the failure modes makes it difficult to develop an accurate method for predicting the structural behaviour of composite truss beams. A simple model was adopted by "Standard specifications for composite steel joists" [20] to estimate the moment capacity of the composite truss by ignoring the contribution of the top chords to the bending resistance [14].

In recent years, the steel-concrete composite space truss, which is made of tubular steel members, has attracted the attention of architects and researchers owing to its aesthetical qualities and higher out-of-plane stability compared with the plane truss. As reported by Reis and Oliveira Pedro [21], the composite space truss with a triangular section was first proposed by Jean Muller and applied in Roize Bridge. Thus far, a few studies have been performed on this type of composite truss. Braz [22] tested a specimen with a midspan of $6 \mathrm{~m}$ and a cantilever span of $1.5 \mathrm{~m}$. An unexpected local failure near the support occurred during the test, which was caused by the large compressive forces in the diagonals. A moment-curvature model was proposed in [22], which exhibited reasonable accuracy. Machacek and Cudejko $[23,24]$ performed an experimental and numerical study on composite steel and concrete trusses to investigate the shearforce distributions along the beams.

Reviewing the literature reveals a lack of studies on the steel-concrete composite space truss, which may hinder the application of this type of structural member. The influence of the degree of the shear connection on the structural performance of the composite truss has not been clarified. Furthermore, design methods are required to estimate the bending capacity of the composite truss. To fill this knowledge gap, this paper presents an experimental and analytical study on the flexural responses of steel-concrete composite truss beams (SCCTBs). Three simply supported composite trusses with different configurations of shear connection studs were evaluated via three-point bending tests. The effects of the shear connectors' configuration on the flexural response of the composite truss were examined. A finite-element (FE) model was developed and validated by the experimental results. A parametric study was conducted to investigate the effects of the degree of the shear connection on the flexural response of the composite trusses. Finally, a design method was proposed for predicting the ultimate capacity, and it exhibited good agreement with the experimental and FE results.

\section{Experimental Program}

2.1. Test Specimens. Three SCCTBs, which consisted of a steel truss, a concrete slab on it, and shear connectors resisting the slippage between them, were tested. The main parameter was the degree of the shear connection (i.e., the quantity of shear connectors). The dimensions of the SCCTB specimens are plotted in Figure 1, and a photograph of the SCCTBs is shown in Figure 2.

A square pyramid structure was selected for the steel truss to achieve sufficient lateral stiffness. The height, width, and length of the steel truss were 500, 500, and $4000 \mathrm{~mm}$, respectively. The steel truss was made of circular tubes with fillet welds connecting them together. The dimensions of the top chord, bottom chord, diagonals, and upper braces were $\Phi 42 \times 3 \mathrm{~mm}^{2}, \Phi 70 \times 5 \mathrm{~mm}^{2}, \Phi 32 \times 4 \mathrm{~mm}^{2}$, and $\Phi 42 \times 3 \mathrm{~mm}^{2}$, respectively (Figure 1).

The concrete slab was $80 \mathrm{~mm}$ deep and $1500 \mathrm{~mm}$ wide, with reinforcement meshes placed on both the top and bottom sides in the concrete slab. The nominal diameter and spacing of the longitudinal reinforcements were 6 and $100 \mathrm{~mm}$, respectively, and those of the transverse reinforcements were 6 and $150 \mathrm{~mm}$, respectively.

Stud connectors were employed to connect the steel truss and the concrete slab (Figure 1). These stud connectors had a diameter of $13 \mathrm{~mm}$ and an ultimate strength of $425 \mathrm{MPa}$. The critical amount of shear connectors was defined as the quantity of shear connectors that made the shear resistance of the shear connectors equal to the yield capacity of both the top and bottom chords. According to Code for design of steel structures [11], the critical amount of shear connectors for the composite truss is 34 . To investigate the effect of the quantity of shear connectors on the flexural response of the composite truss, three quantities of shear connectors were selected: 30, 34, and 42 (corresponding to specimens B1, B2, 


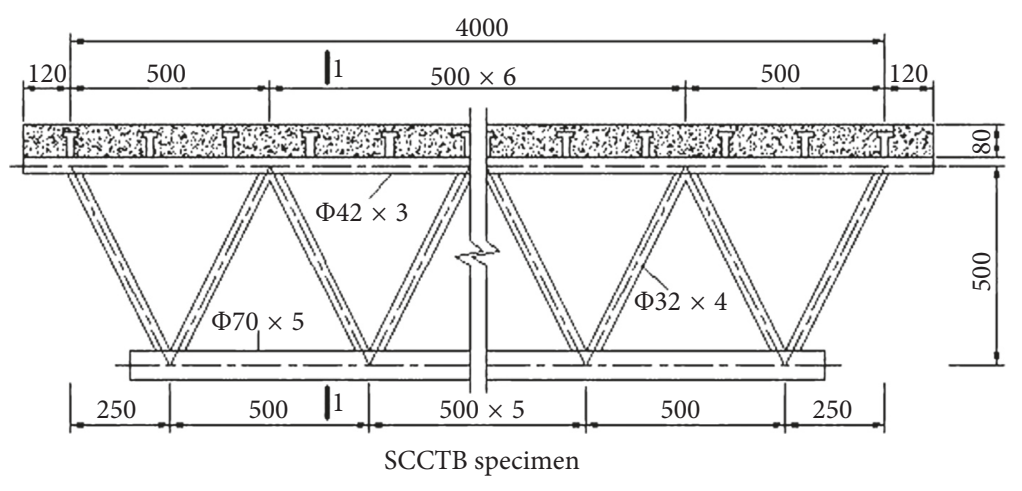

(a)

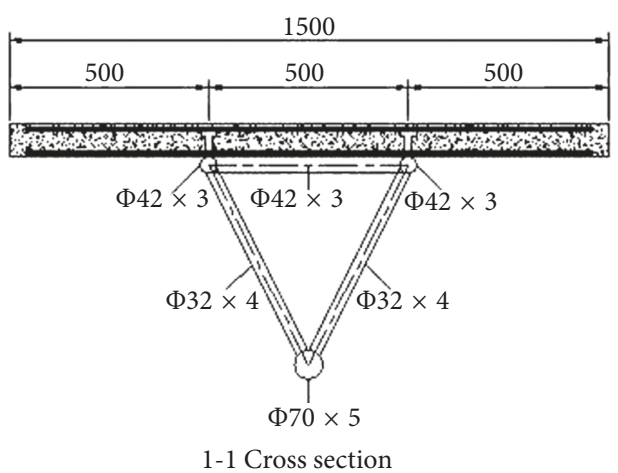

(b)

Figure 1: Dimensions of the SCCTB specimens.

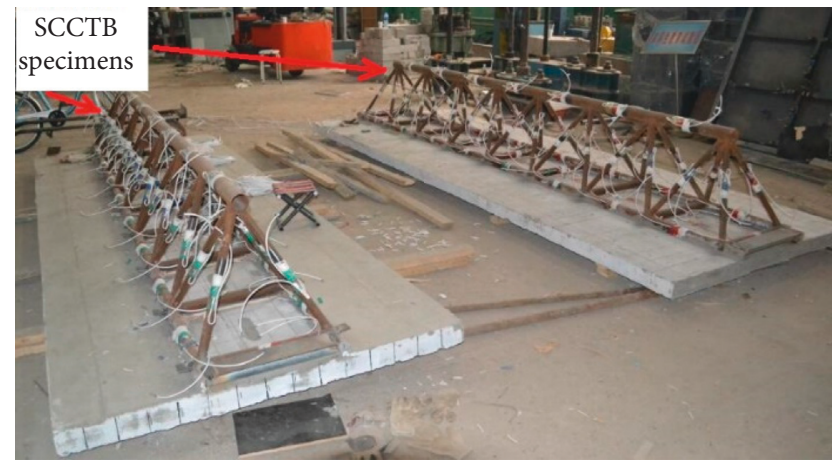

FIgURE 2: Photograph of the SCCTB specimens.

and B3, respectively). A shear interaction factor $k$ is defined as the ratio of critical amount of shear connectors to actual amount of stud connectors. As a result, the shear interaction factors for specimen B1, B2, and B3 are 0.88, 1.0, and 1.24, respectively.

2.2. Materials. The steel truss was manufactured using Q345B steel with a nominal yield strength of $345 \mathrm{MPa}$. Three tensile coupons, which were cut from steel tubes, and three reinforcement coupons were tested to obtain the material properties of the steel tubes in the truss and the rebars in the concrete slab. The tensile-coupon tests were conducted in accordance with GB/T228-2010 [25]. The test results, including the yield strength $f_{\mathrm{y}}$, ultimate strength $f_{\mathrm{u}}$, and elongation, are presented in Table 1 (average values).

The concrete slab was made of ordinary Portland cement concrete with a strength grade of C30. When mixing concrete, the ratio of raw materials is $1: 1.6: 3: 0.5$ (by weight) for cement: sand: coarse aggregate: water. Three concrete cubes with dimensions of $150 \mathrm{~mm} \times 150 \mathrm{~mm} \times 150 \mathrm{~mm}$ were prepared and axially compressed in accordance with GB/ T50081 [26] to obtain the mechanical properties. The measured material properties of the concrete slab are presented in Table 1 (average values). Here, the cubic strength $f_{\text {cu0 }}$ was converted into the cylindrical strength $f_{\mathrm{c}}$, and $E_{\mathrm{c}}$ represents the elastic modulus.
2.3. Test Setup and Instrumentation. The composite truss was simply supported on steel bases, in which roller support was achieved by placing steel rods between the beam and the bases, as shown in Figure 3(a). A concentrated load was applied at the middle of the concrete slab through a $1000 \mathrm{kN}$ hydraulic Jack connected to a self-balancing reaction frame.

Dial gauges were placed along the composite truss with a spacing of $1 / 8$-span to monitor the slippage between the concrete slab and the steel truss, as shown in Figure 3(b). The dial gauges were fixed on the bottom surface of the concrete slab using a custom-manufactured holder, which was mounted in the concrete slab. The spindles of the dial gauges were in contact with a timber plate, which was glued to the top chord of the steel truss. Therefore, the relative movement between the concrete slab and the steel truss could be measured.

The LVDTs were located at 1/8-span positions along the length of the SCCTB specimen to measure the deflection, as shown in Figure 3(c). The vertical LVDTs were placed on the bottom surface of the concrete slab and the top chord of the steel truss. In addition, two vertical LVDTs were placed at the supports to measure their settlements.

Longitudinal strain gauges were affixed to the top side of the concrete slab and the top chords at $1 / 8$-span positions along the beam. Longitudinal strain gauges were also attached to the middle part of each chord and diagonal, as shown in Figure 3(d).

All the data, including the loads, deflections, and strains, were simultaneously acquired by a dataTaker and recorded on a personal computer, as shown in Figure 3(e).

2.4. Test Procedures. A concentrated force was acted at midspan by the hydraulic jack. To avoid the local concrete crushing, a loading beam was designed to disperse concentrated force, as shown in Figure 3(e). A preload, which was approximately $10 \%-20 \%$ of the estimated ultimate load obtained via FE analysis, was first applied to ensure that the specimen and equipment were working properly. After everything was examined, the test was started. When the specimen was in the elastic phase, the load was applied with a rate of $20 \mathrm{kN} / \mathrm{min}$ until the deflection of the specimen increased rapidly, which indicated a nonlinear response. For 
TABle 1: Material properties.

\begin{tabular}{|c|c|c|c|c|c|c|}
\hline Material & $f_{\mathrm{y}}(\mathrm{MPa})$ & $f_{\mathrm{u}}(\mathrm{MPa})$ & Elongation & $f_{\mathrm{cu}, 0}(\mathrm{MPa})$ & $f_{\mathrm{c}}(\mathrm{MPa})$ & $E_{\mathrm{c}}(\mathrm{MPa})$ \\
\hline Steel & 437.0 & 542.4 & 0.287 & - & - & - \\
\hline Reinforcement bar & 405.7 & 550.8 & 0.318 & - & - & - \\
\hline Concrete & - & - & - & 35.0 & 23.4 & 31324 \\
\hline
\end{tabular}

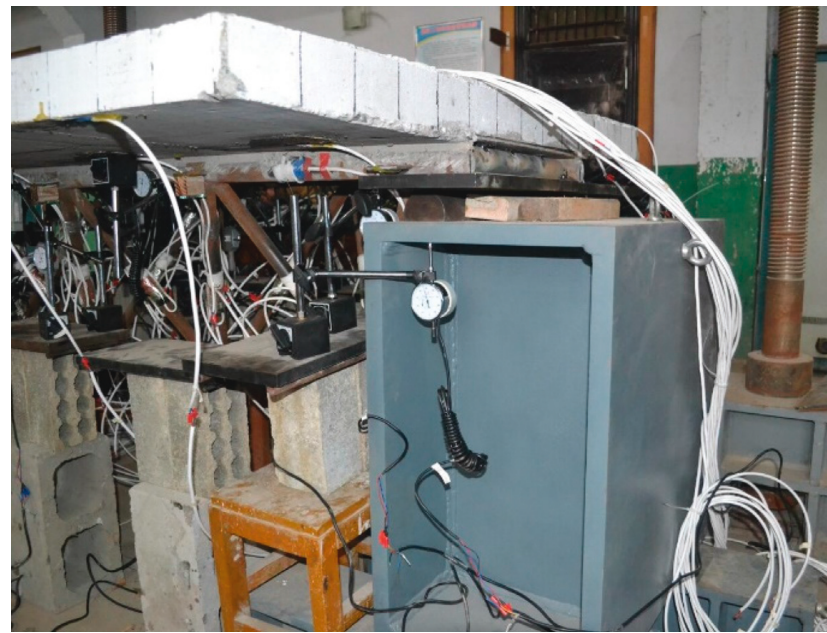

(a)

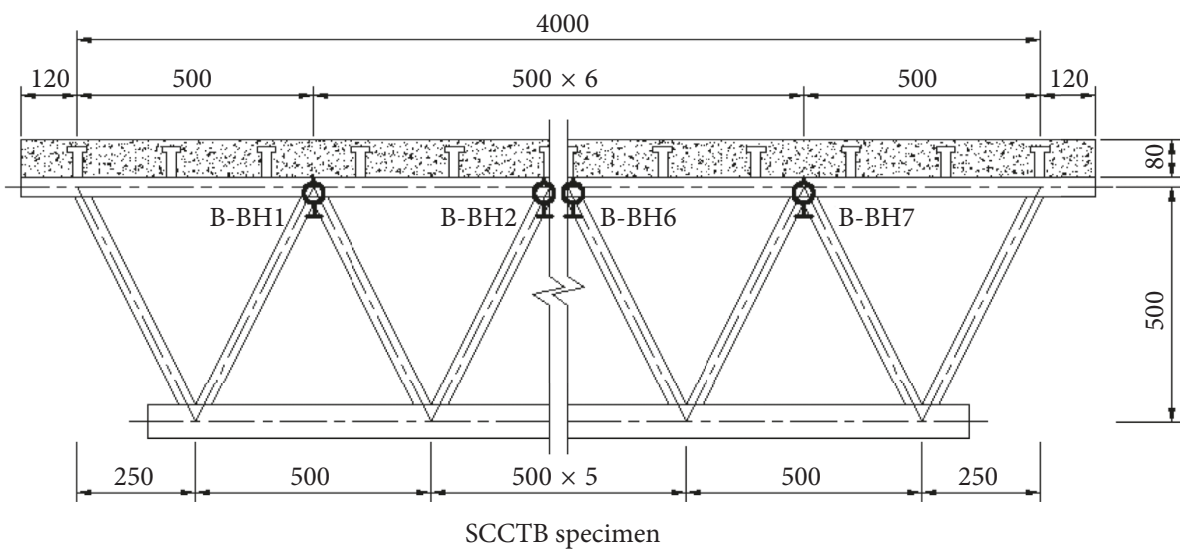

(b)

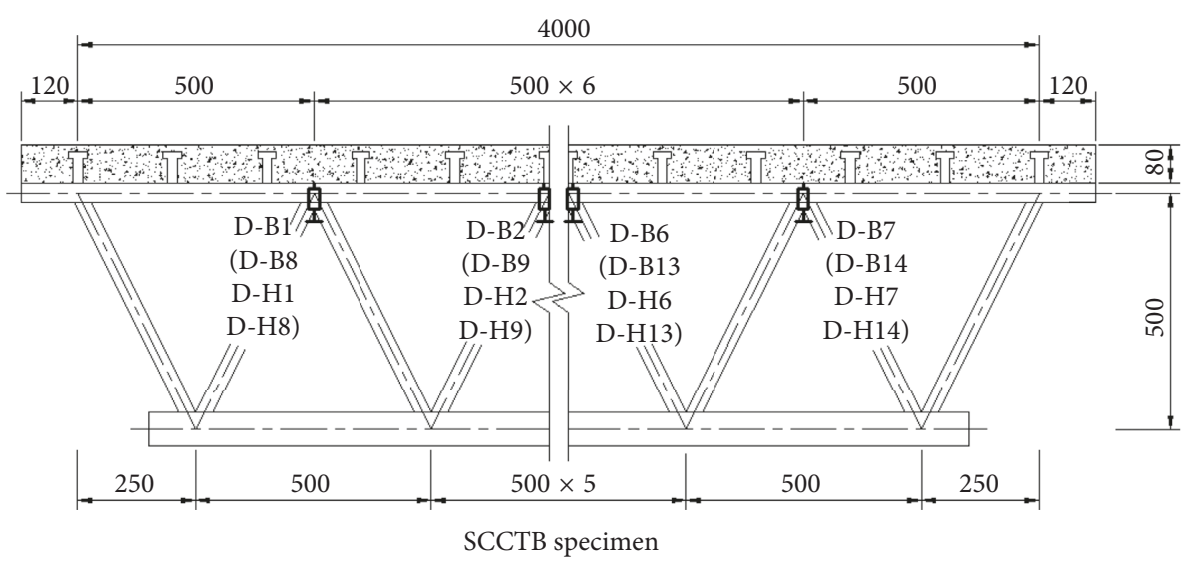

(c)

Figure 3: Continued. 


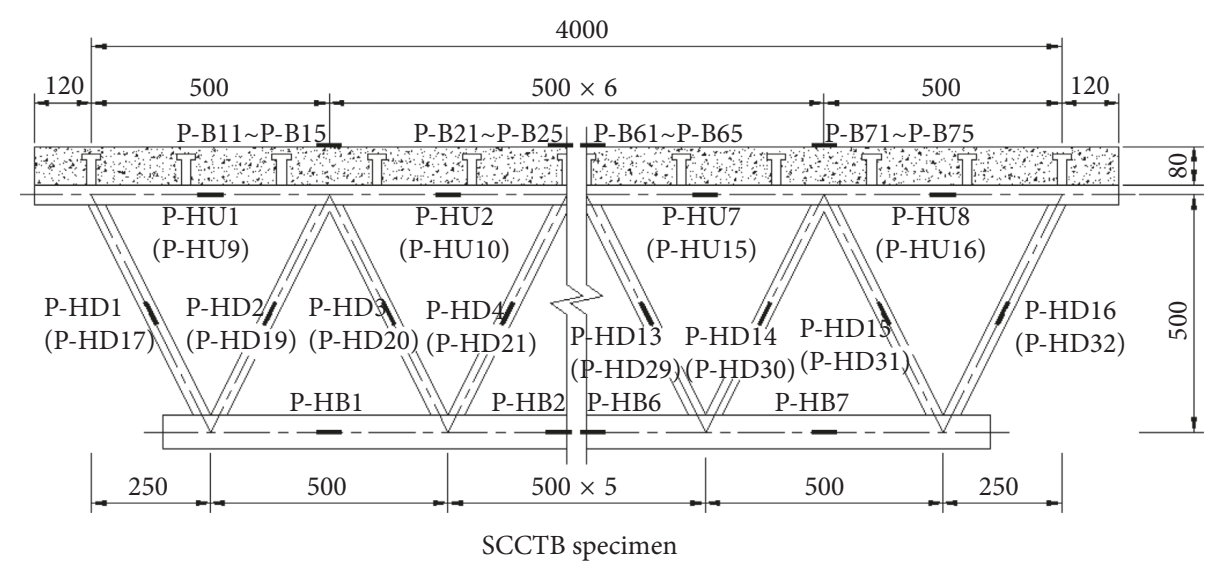

(d)
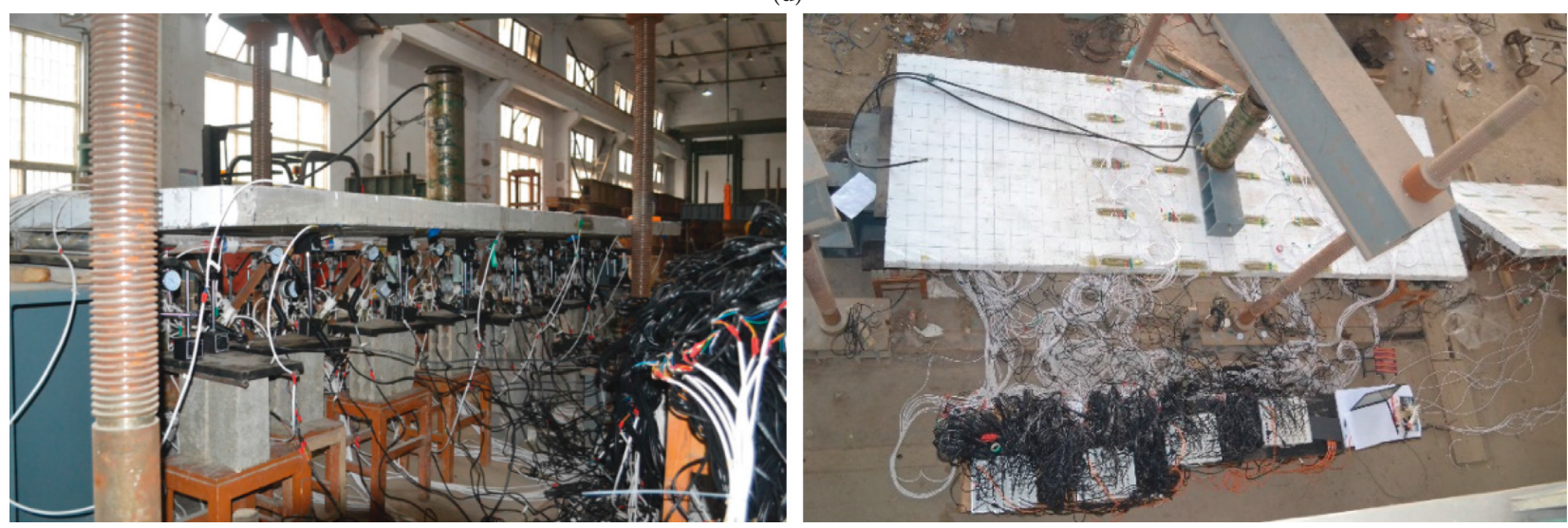

(e)

FIgURE 3: Arrangement of the measurement points for the SCCTB specimens. (a) Simply support. (b) Dial gauges. (c) LVDTs. (d) Strain gauges. (e) Photos of SCCTB specimens.

each loading level, the load was kept constant for approximately $3 \mathrm{~min}$ to record the stable data. After the nonlinear region was reached, the loading form was changed to displacement control with a rate of $5 \mathrm{~mm} / \mathrm{min}$.

\section{Test Phenomena and Failure Modes}

3.1. Test Phenomena. The test phenomena of the SCCTB specimens comprised three phases. (1) At the beginning of the loading process, the deformation of the SCCTB specimens was inconspicuous, signifying the elastic phase. (2) As the load increased, the behaviour of the SCCTB specimens entered the nonlinear region, leading to rapid deformation. (3) When the load increased to approximately $85 \%$ of the ultimate load, cracks appeared at the bottom surface of the concrete slab. Meanwhile, the cracks developed with the increase of the load, until the SCCTB specimens collapsed.

The cracks initially appeared in the middle area of the concrete slab. The amount of cracks increased with the load. Finally, the cracks expanded and ran through the concrete slab, as shown in Figure 4. The cracks on the bottom side of the concrete slab indicate that the neutral axis was located in the slab; thus, tensile stress was induced on the bottom surface of the slab. The failure of the composite truss was caused by the yielding of the bottom chords and the concrete

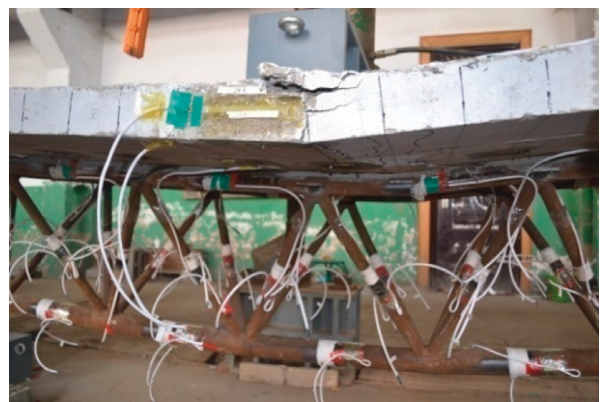

FIgURE 4: Failure mode of the composite truss.

crushing of concrete slab. After specimen failure, extensive cracks were observed on the bottom side of the concrete slab.

3.2. Load-Deflection Curves. The load-deflection curves of the specimens are shown in Figure 5, where the deflection is the deflection at the midspan subtracted by the support settlement. The applied load increased linearly until reaching approximately $200 \mathrm{kN}$, indicating that the specimen was in the elastic phase. The stiffness (slope of the load-deflection curve) was almost identical for the specimens, i.e., approximately $10 \mathrm{kN} / \mathrm{mm}$. Then, the nonlinear response 


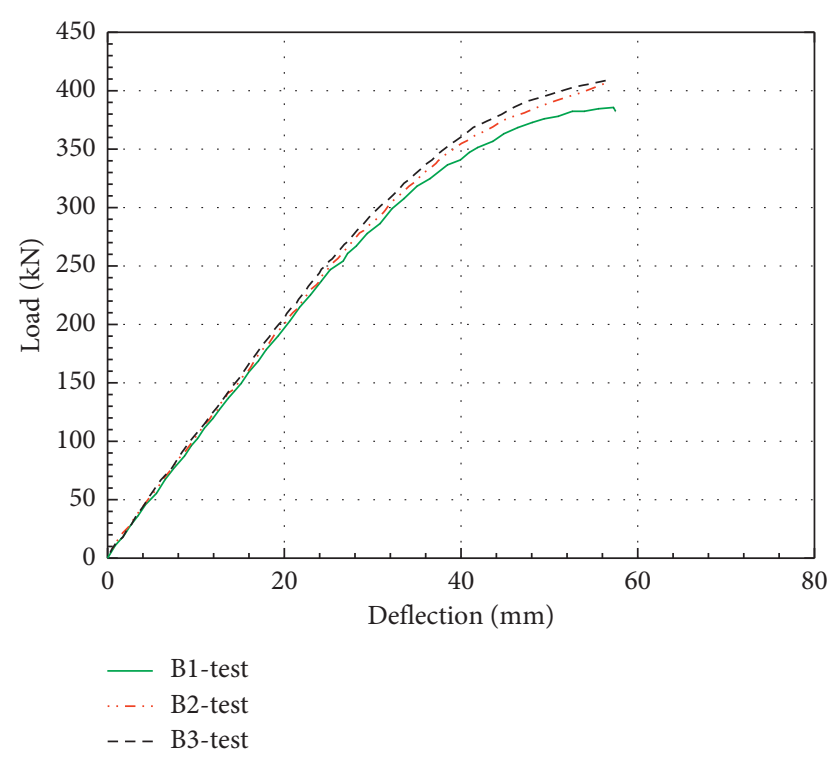

Figure 5: Load-deflection curves.

was observed. The curves deviated from each other owing to the different connector arrangements. Finally, the concrete slab at the middle of the beam specimen crushed, signifying the failure mode of SCCTBs. Meanwhile, the ultimate bearing capacity of the designed beam specimens was mainly controlled by the collapse of the concrete slab. On the one hand, a concentrated force was applied at the middle of the beam specimen so that a large local compressive stress was generated at the loading point. On the other hand, the bending moment also created a compressive stress at the loading point of the concrete slab. Hence, multidirectional compressive stress field existed in this region, leading to an easy concrete crushing of these designed SCCTBs. As shown in Figure 5 and Table 2, the stiffness of specimen B1 decreased most rapidly, with the lowest ultimate load of $385.6 \mathrm{kN}$, while specimen B3 had the highest capacity of $408.7 \mathrm{kN}$. The stud connectors' distribution affected the mechanical behaviours of the composite truss. The stiffness and ultimate load of the composite truss increased with the shear connection factor $(k)$.

3.3. Load-Slippage Curves. The load-slippage curves of the tested specimens are shown in Figure 6, in which the slippage is the relative movement between the concrete slab and the top chord at the midspan. Initially, the load increased linearly with the increase of the slippage, as the composite truss was in the elastic phase. After reaching approximately $300 \mathrm{kN}$, the curves showed nonlinearity, similar to the load-deflection curves. The connector quantity significantly affected the slippage of the composite truss. Specimen B1 exhibited the lowest stiffness and largest slippage, because the shear interaction factor $(k)$ was $<1$, indicating a partial shear connection. With the increase of the connector quantity, the slippage decreased, as shown in Figure 6 . When the shear interaction factor increased from 1.0 (B2) to 1.24 (B3), the load-slippage curve did not change
TABLE 2: Ultimate load (kN).

\begin{tabular}{lccc}
\hline Specimen & Test & FE & RE (\%) \\
\hline B1 & 385.6 & 401.4 & 4.97 \\
B2 & 405.9 & 415.4 & 2.34 \\
B3 & 408.7 & 419.7 & 2.68 \\
Mean & - & - & 3.33 \\
\hline
\end{tabular}

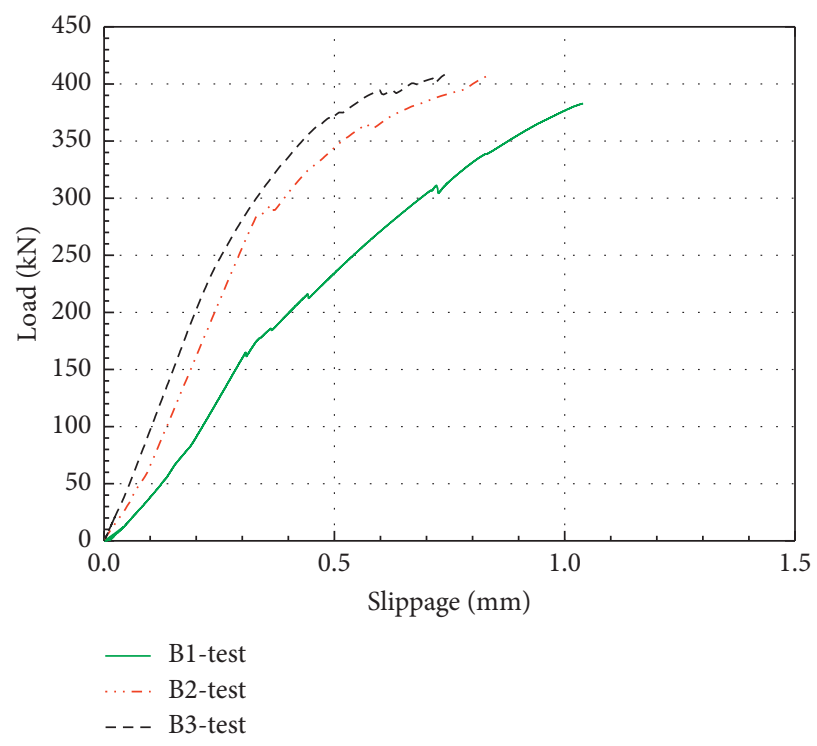

Figure 6: Load-slippage curves.

significantly. It is concluded that after a full shear connection was reached (i.e., $k \geq 1$ ), the influence of the connector quantity was not evident.

3.4. Load-Strain Curves. The load-strain curves for the bottom chord and for the concrete slab at the midspan are presented in Figures 7 and 8, respectively. In Figure 7, the load-strain curves are linear and almost identical. When the truss approached failure, the strain in the bottom chord did not increase dramatically, confirming that the failure of the composite truss was not caused by bottom-chord yielding. In contrast, the load-compressive strain curves for the concrete slab (Figure 8) were highly nonlinear, and the strain reached approximately 0.003 at the failure load. As the strain gauges were located at the midheight (i.e., half of the slab thickness), the compressive strain on the top surface of the concrete slab at the failure load was expected to be significantly higher than 0.003 , causing the crush failure of the concrete slab. The influence of the connector quantity on the stress-strain curve was not evident, likely because the neutral axis was in the concrete slab.

\section{FE Simulation}

4.1. FE Modelling. A three-dimensional (3D) nonlinear FE model was developed using the commercial FE software ANSYS. The geometric dimensions of the FE model were 


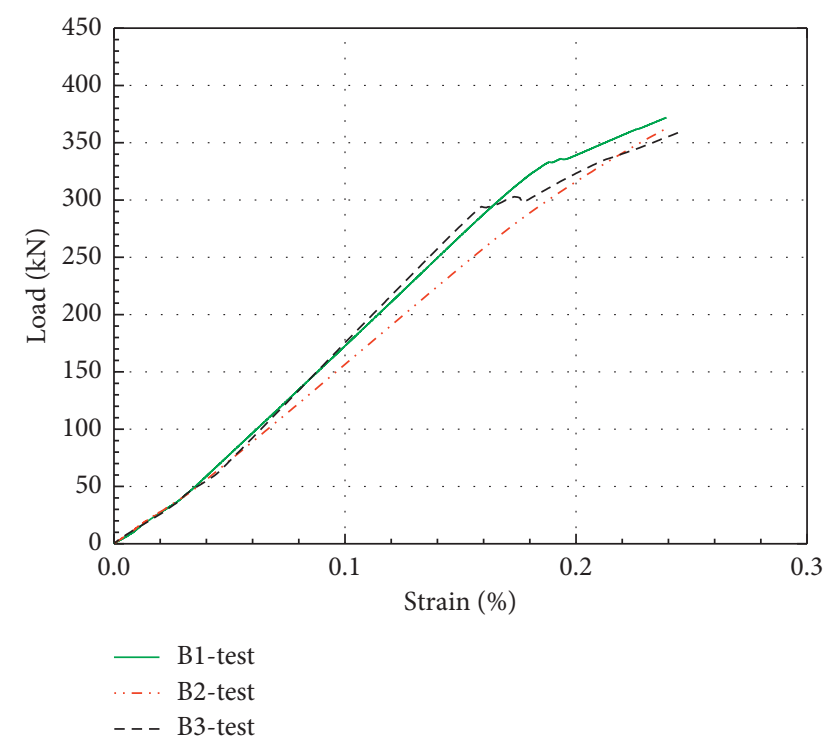

FIgURE 7: Curves of load-tensile strain in the bottom chord.

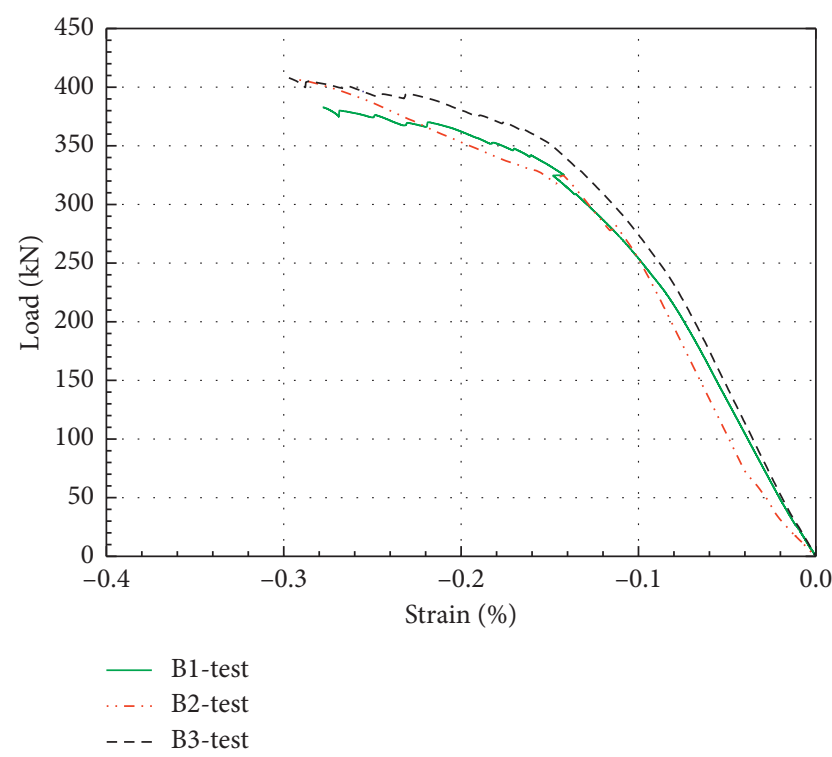

Figure 8: Curves of load-compressive strain in the concrete slab.

identical to those of the tested specimens, as shown in Figure 1.

The concrete slab was modelled with the eight-node solid element SOLID65 having three degrees of freedom at each node (i.e., translations in the $x, y$, and $z$ axes). SOLID65 is capable of cracking under tension and crushing under compression. The rebars in the concrete slab were modelled by the 3D spar element LINK8, which is a uniaxial tensioncompression element with three degrees of freedom at each node. The members in the steel truss were modelled by the 3D linear beam element BEAM188, which is suitable for analysing slender to moderately thick beam structures. BEAM188 has six degrees of freedom at each node (i.e., three translations and three rotations). The connectors were also modelled by BEAM188, and the slippage and vertical deformation between the concrete slab and top chord were modelled by the nonlinear spring element COMBIN39. COMBIN39 is a unidirectional element with a generalised force-deflection capacity and three degrees of freedom (translation) at each node. An overview of the 3D FE model is shown in Figure 9. The element types for each component are shown in Figure 10, along with the mesh.

According to [27], it is assumed that the concrete has ideal plasticity after reaching the ultimate strength. Figure 11 illustrates the simplified stress-strain relationship $(f-\varepsilon)$ for concrete, which was converted into piecewise linear curves for easy inputting to ANSYS. During compression, the stress increased linearly until reaching $0.3 f_{\mathrm{c}}$ and the strain at $0.3 f_{\mathrm{c}}$ was calculated using equation (2), where $E_{\mathrm{c}}$ is the elastic modulus of concrete. In the nonlinear region, the stressstrain curve was obtained using equation (3) [28], where $\varepsilon_{0}$ is the strain at the maximum concrete strength $f_{\mathrm{c}}$, as calculated via equation (4). Perfectly plastic behaviour was assumed when the concrete reached the maximum concrete strength. The performance of concrete under tension is approximately linear up to the tensile strength of the concrete. After this point, the tensile strength decreases to zero [29]. The tensile strength of the concrete was not recorded during the experiment; thus, it was considered as $10 \%$ of the compressive strength [30].

$$
\begin{aligned}
E_{\mathrm{c}} & =\frac{f}{\varepsilon}, \\
f & =\frac{E_{\mathrm{c}} \varepsilon}{1+\left(\varepsilon / \varepsilon_{0}\right)^{2}}, \\
\varepsilon_{0} & =\frac{2 f_{\mathrm{c}}}{E_{\mathrm{c}}} .
\end{aligned}
$$

An elastic-linear hardening model was used to define the uniaxial stress-strain relationship for the steel materials, including the truss members, rebars in the concrete slab, and shear connectors (Figure 12). The stress-strain relationship for steel was assumed to be identical under tension and compression. The key parameters in Figure 12, such as $f_{\mathrm{y}}, f_{\mathrm{u}}$, and $\varepsilon_{\mathrm{u}}$, were obtained via the tensile coupon test (Section 2.2).

In order to simulate the slip effect between the concrete slab and the upper chord and transfer the force of the stud connector to the concrete slab effectively, the shear connector is simulated in the following way: (1) beam 188 is used to simulate the part of the stud connector in the concrete slab and (2) COMBIN39 element is used to simulate the part of the stud connector between the concrete slab and the upper chord. For the spring (COMBIN39) element, the relative movement between the top chord of truss and the concrete flange is taken into account, as illustrated in Figure 13. The analytical relationship that was considered for the headed shear connectors was presented by Ollgaard et al. [10]. This relationship is given by the following equation:

$$
F_{i}=F_{\mathrm{u} 0}\left(1-e^{-0.7 \Delta_{i}}\right)^{0.4}
$$




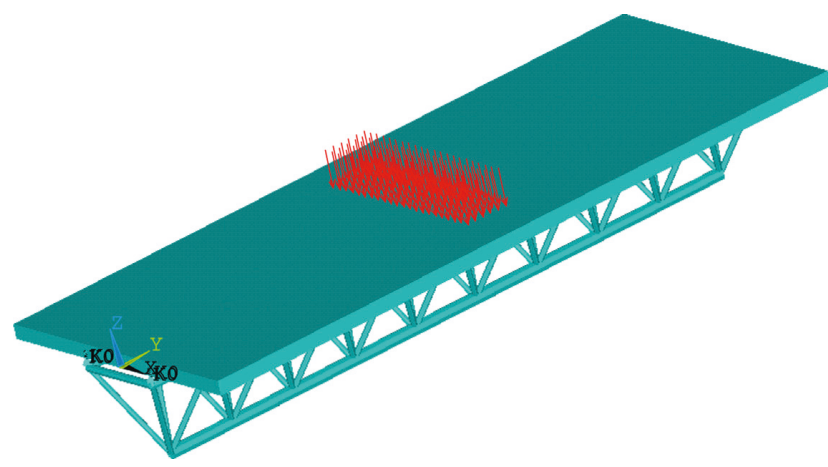

FIgURE 9: FE model.

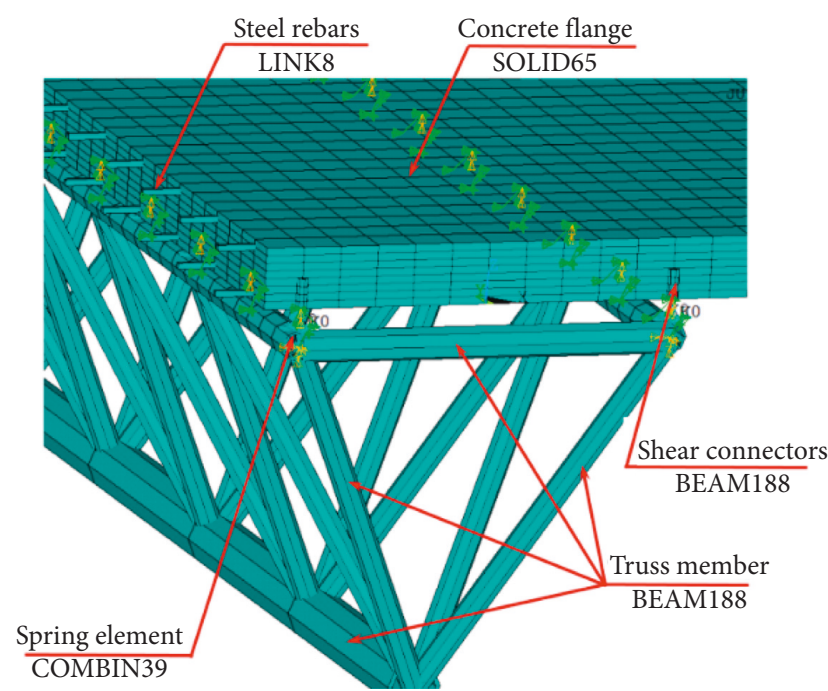

Figure 10: FE mesh.

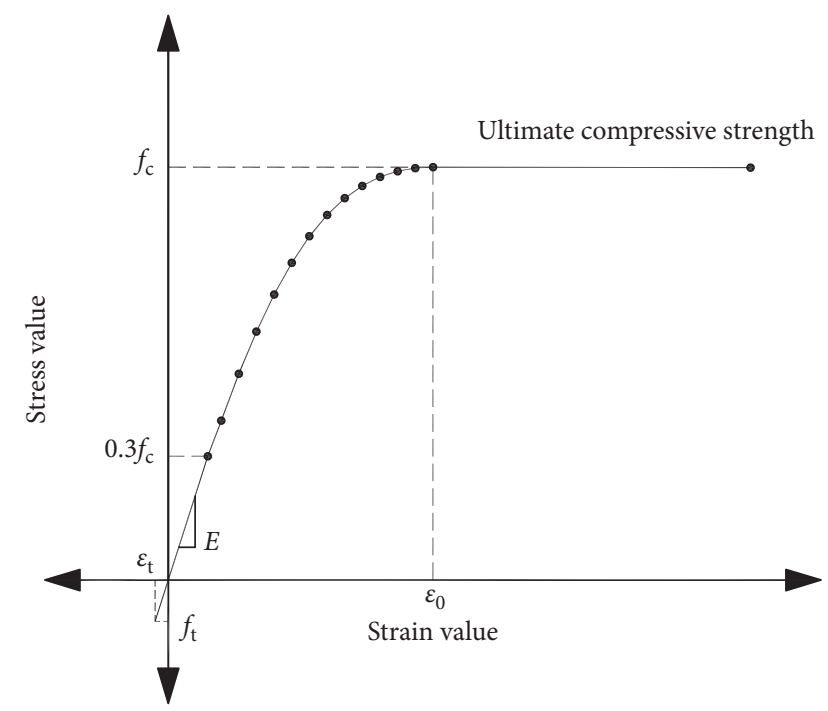

Figure 11: Stress-strain relationship for concrete.

where $F_{i}$ is the horizontal shear force in the shear connector, $F_{\mathrm{u} 0}$ is the ultimate capacity of the shear connector, and $\Delta_{i}$ is the slippage between the concrete flange and the top chord of the truss.

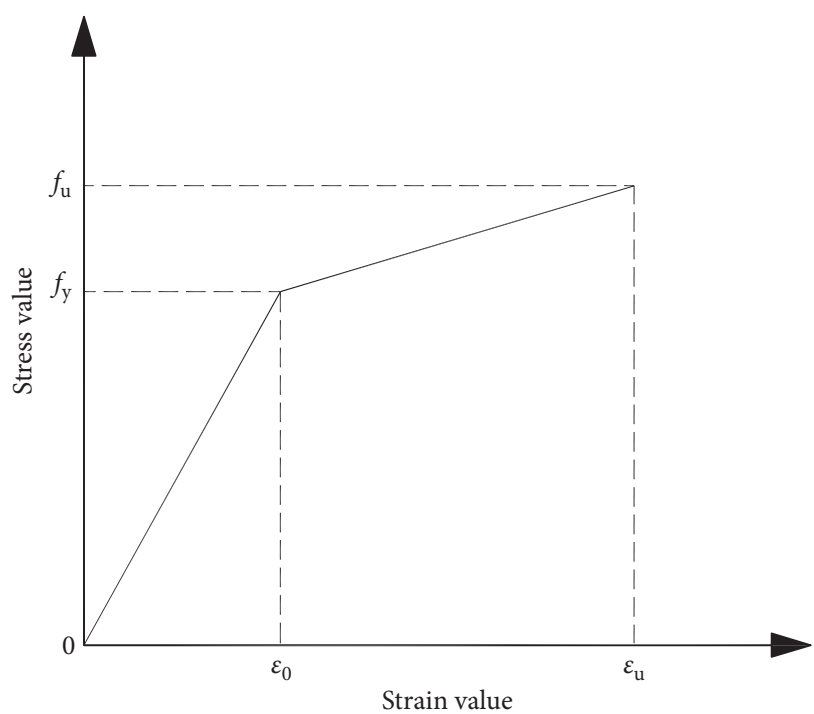

FIgURE 12: Stress-strain relationship for steel.

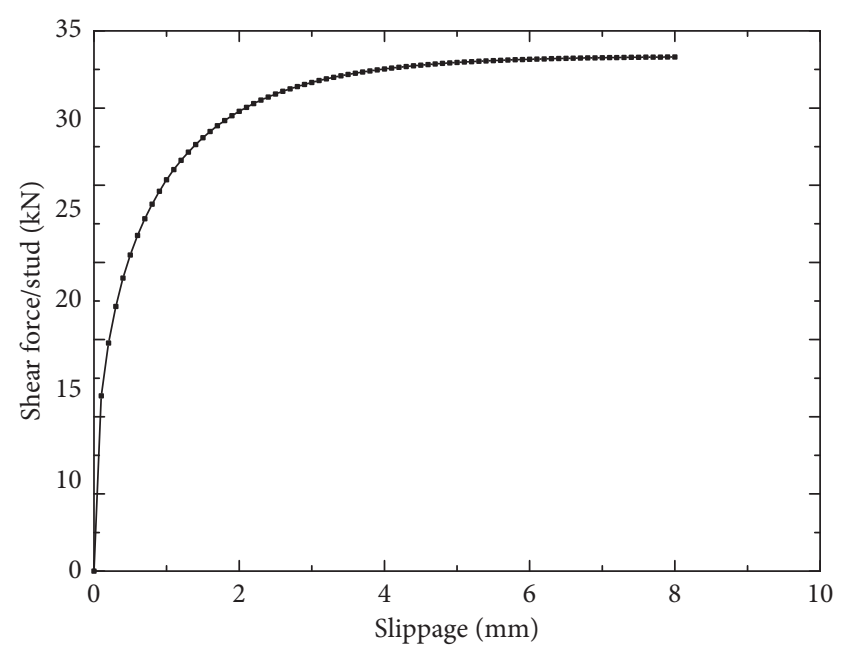

FIGURE 13: Shear force-slippage curve for the shear connectors.

The normal stiffness was calculated as follows:

$$
K_{\mathrm{n}}=\frac{E A}{L},
$$

where $K_{\mathrm{n}}$ is the normal stiffness, $E$ is the elastic modulus of the shear connector, and $A$ is the cross-sectional area of the shear connector.

4.2. Model Verification. A comparison of the load-deflection curves obtained from the experiments and the FE analysis is shown in Figure 14. Generally, the FE curves agreed well with the experimental curves. The ultimate-capacity relative error (RE) between the FE analysis and the experimental test was $<5 \%$ (Table 2 ). The ultimate deflection obtained via the FE analysis was larger than the corresponding experimental value. This overestimation of the deflection was probably caused by the assumption in the concrete constitutive model that the concrete remained constant after reaching $\varepsilon_{0}$ 


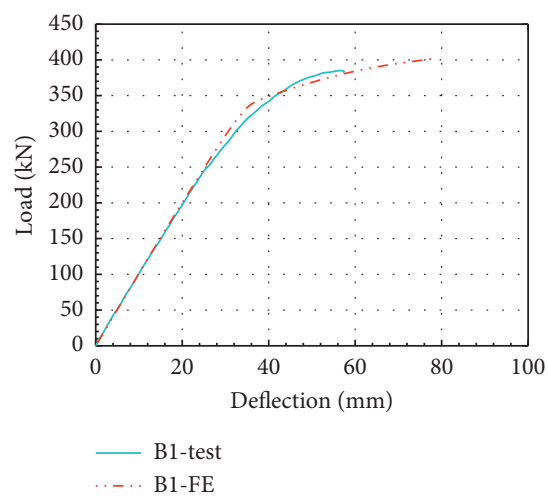

(a)

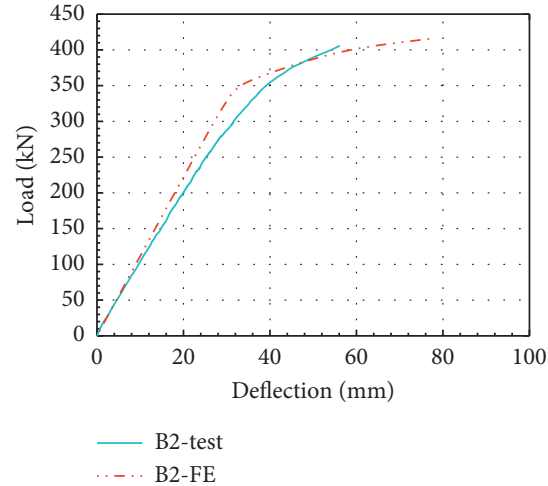

(b)

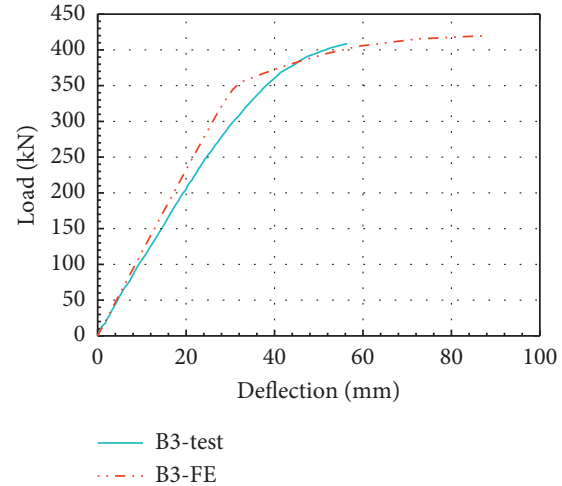

(c)

FIgURE 14: Comparison of the load-deflection curves from the test and FE analysis.

(Figure 11). Figure 15 shows a comparison of the loadslippage curves from the experimental test and FE analysis, where the slippage is the relative movement between the concrete slab and the top chord at the midspan. The FE curves agree well with the experimental curves for specimens B2 and B3. The discrepancy for specimen B1 may be caused by errors introduced during the experiment. Figure 16 shows a comparison of the load-strain curves obtained from the experiments and FE analysis, which exhibit good agreement. The relative error of the load-strain curves between the test and $\mathrm{FE}$ analysis was $<5 \%$. Overall, the $\mathrm{FE}$ results agree well with the experimental results, confirming the accuracy and reliability of the FE model. As described in Section 4.3, this FE model was used to conduct a parametric study to investigate the influence of the shear connectors on the flexural response of the composite truss.

4.3. Effect of Shear Connectors. As discussed in Section 4.2, the FE results agreed well with the experimental results, confirming the accuracy and reliability of the FE model. A parametric study was conducted to derive formulas for predicting the bending capacity of the composite truss.

To characterize the collaborative performance between flange plate and steel truss of composite truss beam, the degree of the shear connection $\eta$ is defined. A larger degree of the shear connection $\eta$ signified a better collaborative performance. Therefore, the degree of the shear connection $\eta$ is an important index to study the mechanical properties of SCCTBs. The degree of the shear connection $\eta$ is calculated using the following equation:

$$
\eta=\frac{n_{\mathrm{s}} F_{\mathrm{u} 0}}{f\left(A_{\mathrm{s} 1}+A_{\mathrm{s} 2}\right)},
$$

where $n_{\mathrm{s}}$ is the quantity of shear connectors within the shear span, $F_{\mathrm{u} 0}$ is the ultimate capacity of the shear connector determined by GB50017 (i.e., equation (1)), $f$ is the ultimate strength of the steel, $A_{\mathrm{s} 1}$ is the cross-sectional area of the top chord in the steel truss, and $A_{\mathrm{s} 2}$ is the cross-sectional area of the bottom chord in the steel truss. $A_{\mathrm{s} 1}$ is the cross-sectional area of the top chord in steel truss and $A_{\mathrm{s} 2}$ is the crosssectional area of the bottom chord in steel truss.
In the parametric study, the degree of the shear connection was changed by varying the spacing of the shear connectors. The relationship between the ultimate capacity of the composite truss and the degree of the shear connection is shown in Figure 17. When $\eta$ was $\leq 1$, the ultimate capacity of the composite truss increased with the degree of the shear connection. When $\eta$ was $>1$, the ultimate capacity of the composite truss did not change with the variation of $\eta$.

The von Mises stress contour of the steel truss at failure (i.e., the ultimate capacity) is shown in Figure 18, and the strain contour of the concrete slab at failure is shown in Figure 19. As shown in Figure 18, most of the top and bottom chords at the midspan were in the plastic region. Figure 19 indicates that the top surface of the concrete slab at the midspan reached its ultimate strength.

\section{Prediction of Ultimate Capacity}

5.1. Assumptions. According to the FE analysis, the following assumptions were made in deriving the formulas for calculating the ultimate capacity of the composite truss.

(1) The tensile strength in the concrete slab is ignored

(2) Only the top and bottom chords in the steel truss are considered in the calculation of the ultimate capacity, and the contribution of the diagonals in the steel truss to resisting the bending moment is ignored

(3) The top and bottom chords are in the plastic region, and the concrete slab is designed as a column under the combined axial load and bending moment (i.e., eccentric compression)

(4) Capacity-prediction formulas are derived separately for two cases: $\eta<1$ and $\eta \geq 1$.

5.2. Prediction Method Based on Full Shear Connection $(\eta \geq 1)$. If $\left(A_{\mathrm{s} 1}+A_{\mathrm{s} 2}\right) f \leq f_{\mathrm{c}} b_{\mathrm{e}} h+f_{\mathrm{sy}}^{\prime} A_{\mathrm{t}}+f_{\mathrm{sy}} A_{\mathrm{b}}$, the plastic neutral axis is located in the concrete slab (Figure 20), and the bending capacity of the composite truss can be determined as follows: 


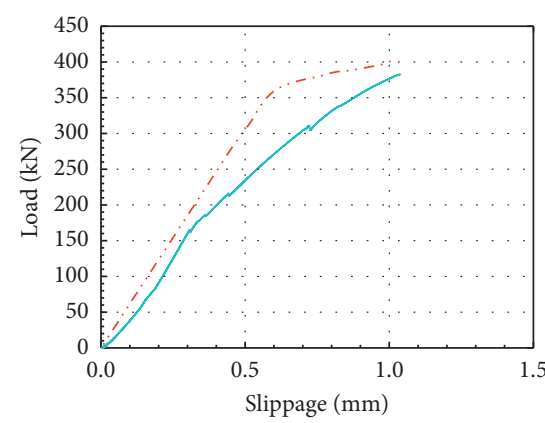

- B1-test

B1-FE

(a)

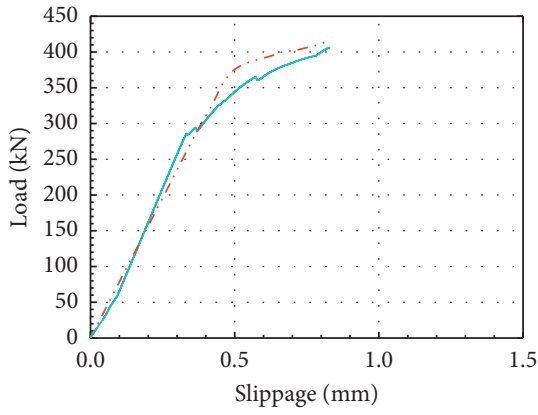

- B2-test

B2-FE

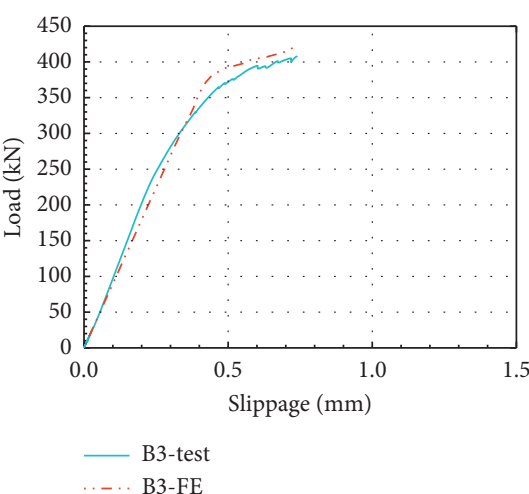

(c)

Figure 15: Comparison of the load-slippage curves from the test and FE analysis.
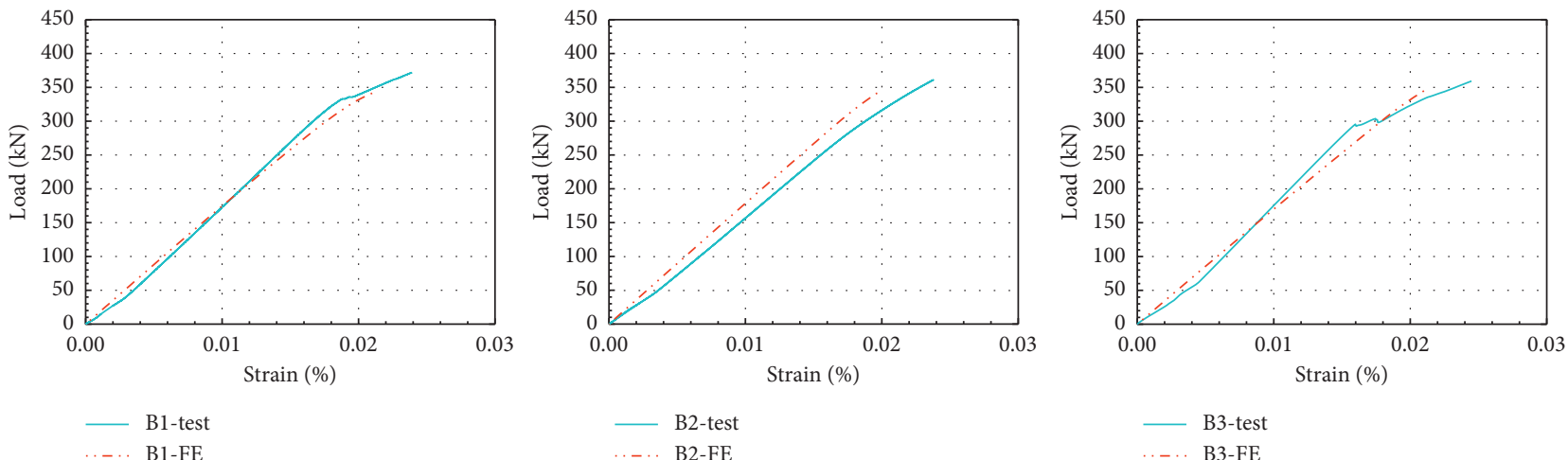

(a)
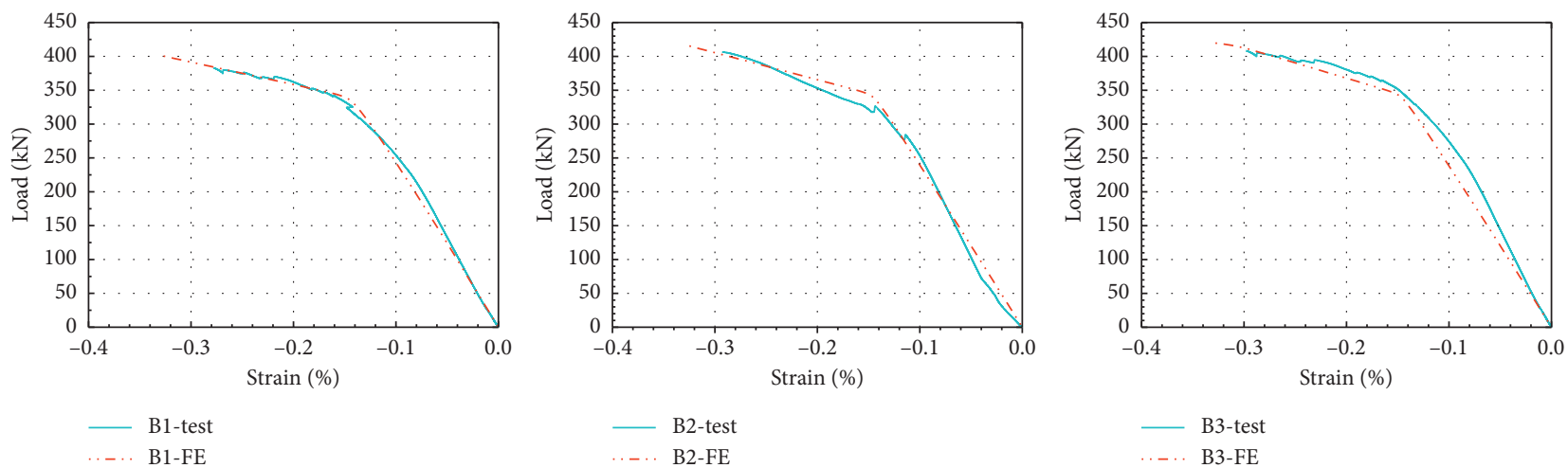

(b)

FIgURE 16: Comparison of the load-strain curves from the test and FE analysis. (a) Bottom chord at midspan. (b) Concrete slab at midspan.

$$
M_{\mathrm{u}}=A_{\mathrm{s} 1} f z_{1}+A_{\mathrm{s} 2} f z_{2}+M_{\mathrm{c}},
$$

where $M_{\mathrm{u}}$ is the bending capacity of the composite truss, $z_{1}$ is the distance between the centre lines of the top chord and concrete slab, $z_{2}$ is the distance between the centre lines of the bottom chord and concrete slab, and $f$ is the ultimate strength of the steel.

The bending capacity of the concrete slab $\left(M_{\mathrm{c}}\right)$ can be calculated using three different stress distributions
(Figure 21). If the axial force $(N)$ calculated using equation (9) is less than the critical compression capacity $\left(N_{\mathrm{u}}\right)$ calculated using equation (10), the concrete slab is under eccentric compression with large eccentricity (i.e., tension failure with tensile reinforcements yielding, as shown in Figure 21(a)). The depth of the equivalent compressive stress block $\left(h_{\mathrm{c}}\right)$ can be determined using equation (11), and $M_{\mathrm{c}}$ can be determined using equation (12): 


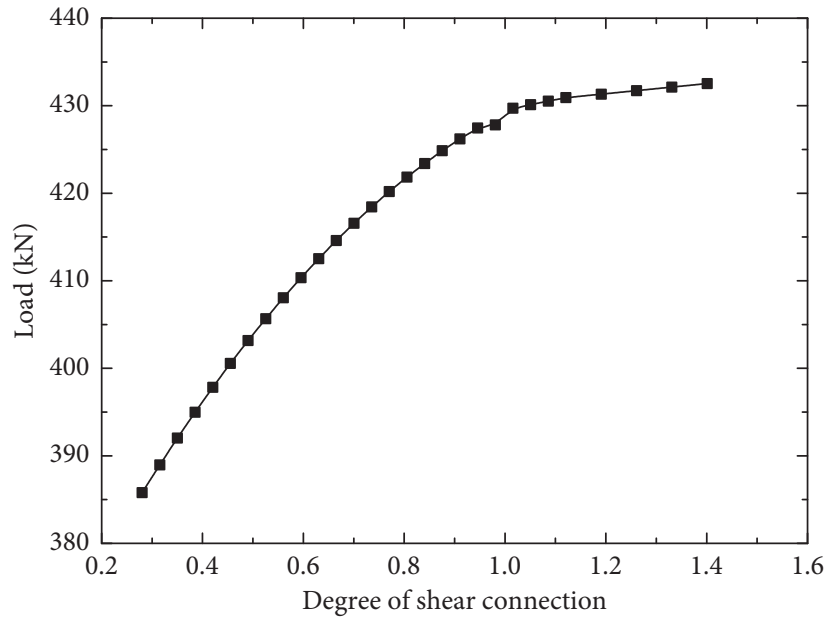

Figure 17: Effect of the degree of the shear connection on the ultimate load.

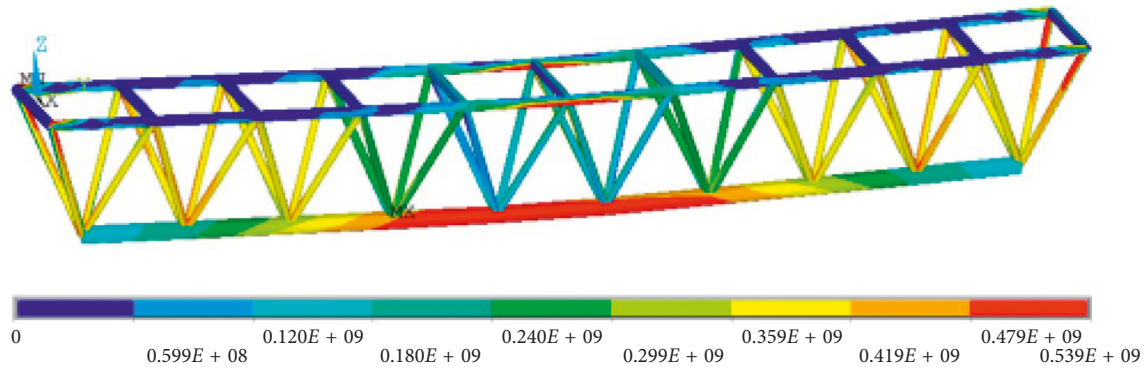

Figure 18: von Mises stress in the steel truss.
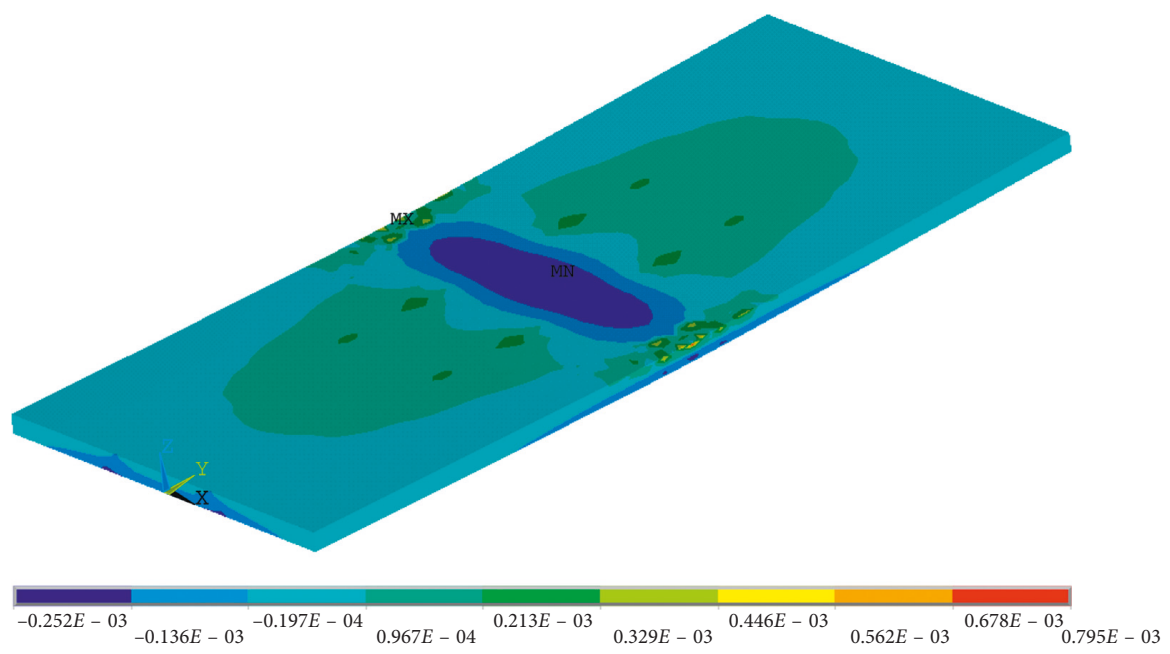

FIgURE 19: Strain in the concrete slab.

$$
\begin{aligned}
N & =\min \left\{\left(A_{\mathrm{s} 1}+A_{\mathrm{s} 2}\right) f, n_{\mathrm{s}} F_{\mathrm{u} 0}\right\}, \\
N_{\mathrm{u}} & =f_{\mathrm{c}} b_{\mathrm{e}} h_{0} \xi_{\mathrm{b}}+f_{\mathrm{sy}}^{\prime} A_{\mathrm{t}}-f_{\mathrm{sy}} A_{\mathrm{b}}, \\
h_{\mathrm{c}} & =\frac{\left(N-f_{\mathrm{sy}}^{\prime} A_{\mathrm{t}}+f_{\mathrm{sy}} A_{\mathrm{b}}\right)}{\left(f_{\mathrm{c}} b_{\mathrm{e}}\right)},
\end{aligned}
$$

$$
M_{\mathrm{c}}=\frac{f_{\mathrm{c}} b_{\mathrm{e}} h_{\mathrm{c}}\left(h-h_{\mathrm{c}}\right)}{2}+f_{\mathrm{sy}}^{\prime} A_{t}\left(\frac{h}{2}-a_{\mathrm{s}}^{\prime}\right)+f_{\mathrm{sy}} A_{\mathrm{b}}\left(\frac{h}{2}-a_{\mathrm{s}}\right),
$$

where $N$ is the axial force in the concrete slab, $N_{\mathrm{u}}$ is the critical compressive capacity for distinguishing large or small eccentricity (i.e., tension or compression failure of the 


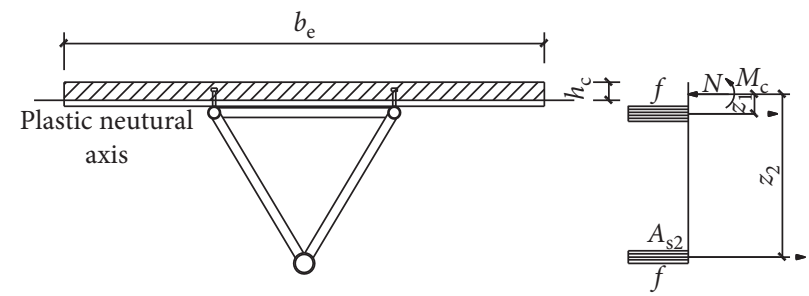

FIgURE 20: Sketches of the composite truss with the plastic neutral axis in the concrete slab.

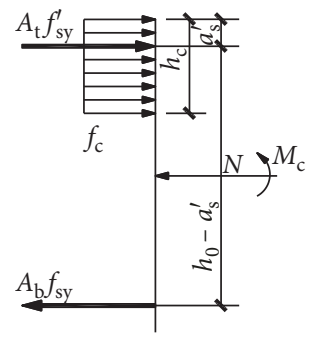

(a)

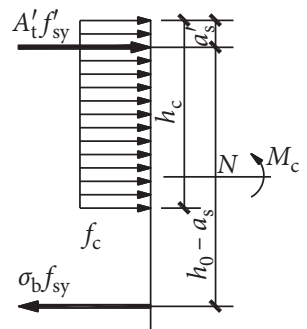

(b)

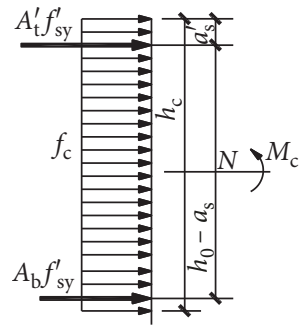

(c)

Figure 21: Diagrams for the calculation of $M_{\mathrm{c}}$.

column), $h$ is depth of cross section of concrete slab, $f_{c}$ is the strength of the concrete, $A_{\mathrm{t}}$ is the cross-sectional area of the reinforcement on the compression side (top side), $A_{\mathrm{b}}$ is the cross-sectional area of the reinforcement on the tension side (bottom side), $f_{\text {sy }}^{\prime}$ is the compressive yield strength of the reinforcement, $f_{\text {sy }}$ is the tensile yield strength of the reinforcement, $b_{\mathrm{e}}$ is the effective width of the concrete slab, $a_{\mathrm{s}}^{\prime}$ is the distance between the centroid of the reinforcements on the compressive side and the extreme compressive fibre of the cross section, and $\xi_{\mathrm{b}}$ is the limit of the neutral-axis depth factor, as shown in Table 3.

If $N>N_{\mathrm{u}}$, the concrete slab is under eccentric compression with small eccentricity (i.e., compression failure with tensile reinforcements unyielding). In this case, $h_{c}$ is determined using equations (13) and (14). If $h_{c}<\left(1.6-\xi_{\mathrm{b}}\right) h_{0}$, the stress distribution in the concrete slab is as shown in Figure 21(b), and $M_{\mathrm{c}}$ can be calculated using equation (15). If $h_{\mathrm{c}}<\left(1.6-\xi_{\mathrm{b}}\right) h_{0}$, the stress distribution is as shown in Figure $21(\mathrm{c}) ; h_{\mathrm{c}}$ can be recalculated using equation (14) by assuming that $\sigma_{\mathrm{sy}}=f_{\mathrm{sy}}^{\prime}$ and $M_{\mathrm{c}}$ is then determined using equation (16):

$$
\begin{gathered}
\sigma_{\mathrm{sy}}=\frac{h_{\mathrm{c}} / h_{0}-0.8}{\xi_{\mathrm{b}}-0.8} f_{\mathrm{sy}}, \\
h_{\mathrm{c}}=\frac{N+\sigma_{\mathrm{sy}} A_{\mathrm{b}}-f_{\mathrm{sy}}^{\prime} A_{\mathrm{t}}}{f_{\mathrm{c}} b_{\mathrm{e}}}, \\
M_{\mathrm{c}}=\frac{f_{\mathrm{c}} b_{\mathrm{e}} h_{\mathrm{c}}\left(h-h_{\mathrm{c}}\right)}{2}+f_{\mathrm{sy}}^{\prime} A_{t}\left(\frac{h}{2}-a_{\mathrm{s}}^{\prime}\right)+\sigma_{\mathrm{sy}} A_{\mathrm{b}}\left(\frac{h}{2}-a_{\mathrm{s}}\right), \\
M_{\mathrm{c}}=f_{\mathrm{sy}}^{\prime} A_{\mathrm{t}}\left(\frac{h}{2}-a_{\mathrm{s}}^{\prime}\right)+f_{\mathrm{sy}}^{\prime} A_{\mathrm{b}}\left(\frac{h}{2}-a_{\mathrm{s}}\right) .
\end{gathered}
$$

If $\left(A_{\mathrm{s} 1}+A_{\mathrm{s} 2}\right) f>f_{\mathrm{c}} b_{\mathrm{e}} h+f_{\mathrm{sy}}^{\prime} A_{\mathrm{t}}+f_{\mathrm{sy}} A_{\mathrm{b}}$, the plastic neutral axis is located in the steel truss (Figure 22). In this case, the bending capacity of the composite truss can be determined using equation (18):

$$
\begin{aligned}
& A_{\mathrm{s} 3}=\frac{\left(A_{\mathrm{s} 1}+A_{\mathrm{s} 2}\right)}{2}-\frac{0.5 b_{\mathrm{e}} h f_{\mathrm{c}}}{f}, \\
& M_{\mathrm{u}}=\left(2 A_{\mathrm{s} 3}-A_{\mathrm{s} 1}\right) f z_{3}+f_{\mathrm{c}} b_{\mathrm{e}} h_{0} z_{4},
\end{aligned}
$$

where $A_{\mathrm{s} 3}$, determined by equation (17), is the compressive area of top chord of steel truss in SCCTBs, $z_{3}$ is the distance between the centre lines of the top and bottom chords, $z_{4}$ is the distance between the centre lines of the bottom chord and concrete slab, and $h$ is the thickness of the concrete slab.

\subsection{Prediction Method Based on Partial Shear Connection} $(\eta<1)$. If the degree of the shear connection is $<1$, the plastic neutral axis is located within the steel truss (Figure 23), and the bending capacity is determined using the following equations:

$$
\begin{gathered}
N=n_{\mathrm{s}} F_{\mathrm{u} 0}, \\
A_{\mathrm{s} 4}=\frac{A_{\mathrm{s} 1}+A_{\mathrm{s} 2}}{2}-\frac{n_{\mathrm{s}} F_{\mathrm{u} 0}}{2 f}, \\
M_{\mathrm{u}}=\left(2 A_{\mathrm{s} 4}-A_{\mathrm{s} 1}\right) f z_{5}+N z_{6}+M_{\mathrm{c}},
\end{gathered}
$$

where $A_{s 4}$, determined by equation (20), is the compressive area of top chord of steel truss in SCCTBs, $z_{5}$ is the distance between the centre lines of the top and bottom chords, and $z_{6}$ is the distance between the centre lines of the bottom chord and the compression region of the concrete slab. The calculation of $M_{c}$ is the same as that introduced in Section 5.2 
TABLE 3: Limit of the neutral-axis depth factor.

\begin{tabular}{lcccc}
\hline Grade of reinforcement & $300 \mathrm{MPa}$ & $335 \mathrm{MPa}$ & $400 \mathrm{MPa}$ & $500 \mathrm{MPa}$ \\
\hline$\xi_{\mathrm{b}}$ & 0.576 & 0.550 & 0.518 & 0.482
\end{tabular}
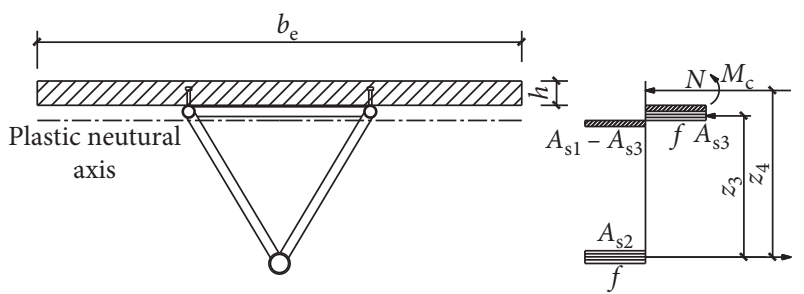

Figure 22: Sketches of the composite truss with the plastic neutral axis in the steel truss.

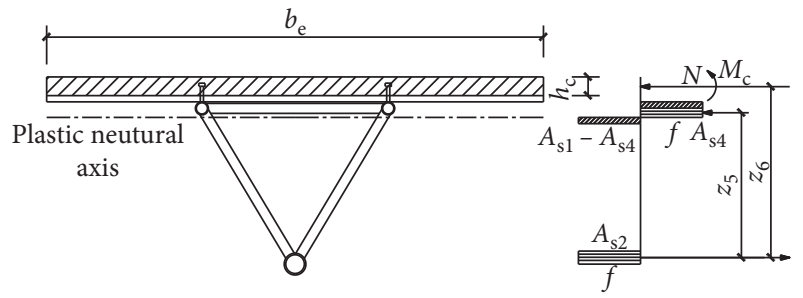

FIGURE 23: Sketches of the composite-truss partial connection stiffness.

for the case where the neutral axis is located within the concrete slab.

5.4. Predicted Results. The bending capacities obtained using the proposed formulas and the experiments are compared in Table 4. Appendix provides a detailed example of calculating the ultimate capacity of the specimen B1. The predicted capacity agrees well with the experimental results (difference of $<10 \%$ ), indicating the reasonability and accuracy of the proposed method.

A comparison between the predicted results and FE results is presented in Figure 24, where $\eta$ is varied from 0.3 to 1.5, covering both full and partial shear connections. As shown in the figure, the predicted values are slightly lower than the FE results, but the difference is $<15 \%$, and the change trends are similar. Thus, the proposed formulas properly consider the effect of the degree of the shear connection on the ultimate capacity of the composite truss.

The results predicted using proposed formulas are generally lower than the experimental and FE results. This slight underestimation is acceptable in engineering practice and falls within a safe margin.

\section{Conclusions}

This paper presents an experimental and theoretical analysis of steel-concrete composite trusses under bending. According to the results, the following conclusions are drawn.
TABle 4: Comparison of the ultimate loads of the SCCTB specimens.

\begin{tabular}{lccc}
\hline No. & Test $(\mathrm{mm})$ & Formulas $(\mathrm{mm})$ & Deviation $(\%)$ \\
\hline B1 & 382.4 & 357.2 & 6.58 \\
B2 & 405.9 & 368.2 & 9.29 \\
B3 & 408.7 & 378.6 & 7.37 \\
Mean & - & - & 7.75 \\
\hline
\end{tabular}

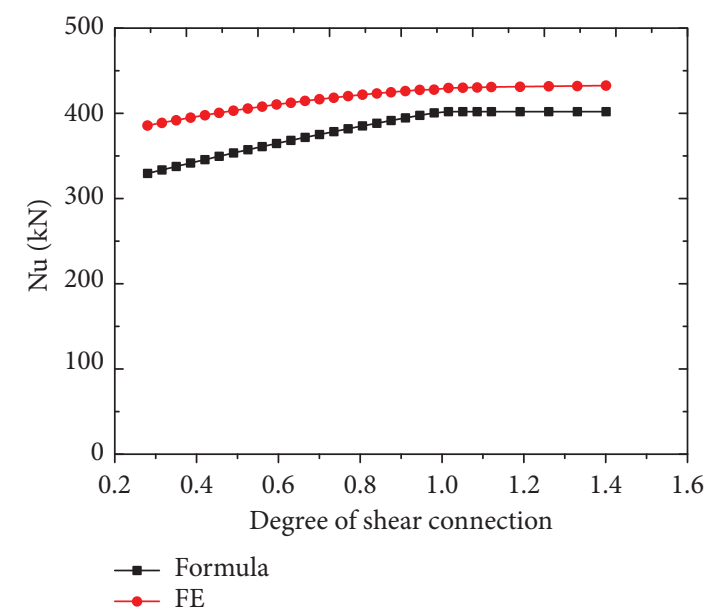

FIgure 24: Comparison between the predicted results and FE results.

The composite truss beams failed via the yielding of the bottom chords, which exhibited ductile behaviour.

The quantity of the shear connectors affected the flexural response of the composite truss. A specimen with a partial shear connection (B1) exhibited a lower capacity and stiffness than specimens with a full shear connection (B2 and B3). When the quantity of shear connectors exceeded the critical amount, the influence of the shear-connector quantity became less significant.

An FE model with proper consideration of the constitutive models of concrete and steel could accurately predict the structural behaviour (i.e., load-deflection, load-slippage, and load-strain curves) of the steel-concrete composite truss, as verified by experimental results. This FE model was employed for a parametric study. The results indicated that if the degree of the shear connection $(\eta)$ is $<1$, the bending capacity increases with $\eta$. However, if $\eta \geq 1$, the effect of $\eta$ on the bending capacity is negligible.

According to the degree of the shear connection, a design method was proposed to predict the ultimate bending capacity of the composite truss. The prediction results agreed well with the experimental results.

\section{Appendix}

According to "GB50017-2018, Standard for design of steel structures, Beijing, China, 2018," $f_{\mathrm{u}}=425 \mathrm{~N} / \mathrm{mm}^{2}$, $A_{\mathrm{s}}=132.7 \mathrm{~mm}^{2}, f_{\mathrm{c}}=23.3 \mathrm{~N} / \mathrm{mm}^{2}$, and $E_{\mathrm{c}}=31324 \mathrm{~N} / \mathrm{mm}$. Therefore, based on equation (1), the shear capacity of a stud connectors is as follows: 


$$
\begin{aligned}
F_{\mathrm{u} 0} & =\min \left(0.43 A_{\mathrm{s}} \sqrt{E_{\mathrm{c}} f_{\mathrm{c}}}, 0.7 A_{\mathrm{s}} f_{\mathrm{u}}\right) \\
& =\min (48.75,39.48) \\
& =39.48 \mathrm{kN} .
\end{aligned}
$$

For the specimen $\mathrm{B} 1, n_{\mathrm{s}}=16$. According to equations (9) and (10),

$$
\begin{aligned}
N & =\min \left\{\left(A_{\mathrm{s} 1}+A_{\mathrm{s} 2}\right) f, n_{\mathrm{s}} F_{\mathrm{u} 0}\right\} \\
& =\min (542.4 \times(735.13+1021.02), 16 \times 39.48) \\
& =631.68 \mathrm{kN}<N_{\mathrm{u}}=23.3 \times 1500 \times(80-8) \times 0.576 \\
& =1449.45 \mathrm{kN} .
\end{aligned}
$$

According to equation (11),

$h_{\mathrm{c}}=\frac{\left(N-f_{\mathrm{sy}}^{\prime} A_{\mathrm{t}}+f_{\mathrm{sy}} A_{\mathrm{b}}\right)}{\left(f_{\mathrm{c}} b_{\mathrm{e}}\right)}=\frac{631680}{(23.3 * 1500)}=18.07 \mathrm{~mm}$.

According to equation (12),

$$
\begin{aligned}
M_{\mathrm{c}}= & \frac{f_{\mathrm{c}} b_{\mathrm{e}} h_{\mathrm{c}}\left(h-h_{\mathrm{c}}\right)}{2}+f_{\mathrm{sy}}^{\prime} A_{\mathrm{t}}\left(\frac{h}{2}-a_{\mathrm{s}}^{\prime}\right)+f_{\mathrm{sy}} A_{\mathrm{b}}\left(\frac{h}{2}-a_{\mathrm{s}}\right) \\
= & 23.3 \times 1500 \times 18.07 \times 30.97+550.8 \times 424.5 \times 36 \\
& +550.8 \times 424.5 \times 36 \\
= & 36.39 \mathrm{kN} \cdot \mathrm{m} .
\end{aligned}
$$

The dimensions for upper chord and bottom chord are $\Phi 42 \times 3 \mathrm{~mm}^{2}$ and $\Phi 70 \times 5 \mathrm{~mm}^{2}$. Therefore, $A_{\mathrm{s} 1}=735.13 \mathrm{~mm}^{2}$ and $A_{\mathrm{s} 2}=1021.02 \mathrm{~mm}^{2}$. In addition, $f=542.4 \mathrm{MPa}$. Hence, based on equation (7), the degree of the shear connection $\eta$ is as follows:

$$
\eta=\frac{16 \times 39480}{542.4(735.13+1021.02)}=0.663
$$

Since $\eta<1$, based on equation (20), the compressive area of top chord of steel truss is

$$
\begin{aligned}
A_{\mathrm{s} 4} & =\frac{0.5\left(A_{\mathrm{s} 1}+A_{\mathrm{s} 2}\right)-0.5 n_{\mathrm{s}} F_{\mathrm{u} 0}}{f} \\
& =\frac{0.5 \times(1021.02+735.13)-0.5 \times 16 \times 36690}{542.4} \\
& =295.77 \mathrm{~mm}^{2} .
\end{aligned}
$$

The distance between the centre lines of upper chord and bottom chord $z_{5}=500 \mathrm{~mm}$, and the distance between the centre line of bottom chord and the centre line of concrete slab $z_{6}=570 \mathrm{~mm}$. According to equation (21), the bending capacity $M_{\mathrm{u}}$ of the specimen B1 can be calculated as follows:

$$
\begin{aligned}
M_{\mathrm{u}}= & \left(2 A_{\mathrm{s} 3}-A_{\mathrm{s} 1}\right) f z_{5}+N z_{6}+M_{\mathrm{c}} \\
= & (2 \times 295.77-735.13) \times 542.4 \times 500+631680 \times 570 \\
& +34850000 \\
= & -38.94+359.78+36.39=357.23 \mathrm{kN} \cdot \mathrm{m} .
\end{aligned}
$$

\section{Data Availability}

The data used to support the findings of this study are available from the corresponding author upon request.

\section{Conflicts of Interest}

The authors declare that they have no conflicts of interest.

\section{Acknowledgments}

The authors gratefully acknowledge the financial support provided by the Natural Science Foundation of China under Grant no. 51808176 and by the National Science Foundation of Hainan Province of China under Grant no. 518QN213.

\section{References}

[1] D. J. Oehlers and M. A. Bradford, Composite Steel and Concrete Structural Members: Fundamental Behaviour, Pergamon, Oxford, UK, 1995.

[2] Y. Alashker, S. El-Tawil, and F. Sadek, "Progressive collapse resistance of steel-concrete composite floors," Journal of Structural Engineering, vol. 136, no. 10, pp. 1187-1196, 2010.

[3] Z. Xiong, J. Deng, F. Liu, L. Li, and W. Feng, "Experimental investigation on the behavior of GFRP-RAC-steel double-skin tubular columns under axial compression," Thin-Walled Structures, vol. 132, pp. 350-361, 2018.

[4] Y. L. Li, X. L. Zhao, R. K. R. Singh, and S. Al-Saadi, "Experimental study on seawater and sea sand concrete filled GFRP and stainless steel tubular stub columns," Thin-Walled Structures, vol. 106, pp. 390-406, 2016.

[5] J. Nie and C. S. Cai, "Steel-concrete composite beams considering shear slip effects," Journal of Structural Engineering, vol. 129, no. 4, pp. 495-506, 2003.

[6] L. An and K. Cederwall, "Push-out tests on studs in high strength and normal strength concrete," Journal of Constructional Steel Research, vol. 36, no. 1, pp. 15-29, 1996.

[7] D. Lam and E. El-Lobody, "Behavior of headed stud shear connectors in composite beam," Journal of Structural Engineering, vol. 131, no. 1, pp. 96-107, 2005.

[8] C. Topkaya, J. A. Yura, and E. B. Williamson, "Composite shear stud strength at early concrete ages," Journal of Structural Engineering, vol. 130, no. 6, pp. 952-960, 2004.

[9] L. Pallarés and J. F. Hajjar, "Headed steel stud anchors in composite structures, part I: shear," Journal of Constructional Steel Research, vol. 66, no. 2, pp. 198-212, 2010.

[10] J. G. Ollgaad, R. G. Slutter, and J. W. Fisher, "Shear strength of stud connectors in lightweight and normalweight concrete," AISC Engineering journal, vol. 8, no. 5, pp. 55-64, 1971.

[11] GB50017-2018, Standard for Design of Steel Structures, China Architecture and Building Press, Beijing, China, 2018.

[12] ANSI/AISC360-10, Specification for Structural Steel Buildings, Standards Australia, Sydney, Australia, 2010. 
[13] European Committee for Standardization EN1994-1-1, Eurocode 4: Design of Composite Steel and Concrete Structures-Part 1-1: General Rules and Rules for Buildings, European Committee for Standardisation, Brussels, Belgium, 2004.

[14] D. Samuelson, "Composite steel joists," Engineering Journal, vol. 39, no. 3, pp. 111-120, 2002.

[15] H. Robinson and E. H. Fahmy, "The design of partially connected composite open-web joists," Canadian Journal of Civil Engineering, vol. 5, no. 4, pp. 611-614, 1978.

[16] A. Brattland and D. J. L. Kennedy, "Flexural tests of two fullscale composite trusses," Canadian Journal of Civil Engineering, vol. 19, no. 2, pp. 279-295, 1992.

[17] A. M. I. Muhammad, "Behaviour of open web steel joist in composite deck floor system," Electronic theses and dissertations, University of Windsor, Windsor, Canada, 2015.

[18] P. Lopez, "In-situ structural evaluation of a steel-concrete composite floor system," Open Access theses, University of Miami, Coral Gables, FL, USA, 2007.

[19] A. Bouchair, J. Bujnak, and P. Duratna, "Connection in steelconcrete composite truss," Procedia Engineering, vol. 40, pp. 96-101, 2012.

[20] SII, Composite Steel Joist Catalog, Steel Joist Institute, Myrtle Beach, SC, USA, 2007.

[21] A. Reis and J. J. Oliveira Pedro, "Composite truss bridges: new trends, design and research," Steel Construction, vol. 4, no. 3, pp. 176-182, 2011.

[22] J. Braz, Composite Truss Bridge Decks, Instituto Superior Técnico, Technical University of Lisbon, Lisbon, Portugal, 2009.

[23] J. Machacek and M. Cudejko, "Longitudinal shear in composite steel and concrete trusses," Engineering Structures, vol. 31, no. 6, pp. 1313-1320, 2009.

[24] J. Machacek and M. Cudejko, "Composite steel and concrete bridge trusses," Engineering Structures, vol. 33, no. 12, pp. 3136-3142, 2011.

[25] The Standardization Administration of China (SAC) GB/ T228-2010, Metallic Materials-Tensile Testing-Method of Test at Ambient Temperature, The Standardization Administration of China (SAC), Beijing, China, 2010.

[26] Ministry of Housing and Urban-Rural Development of the People's Republic of China (MOHURD) GB/T50081-2016, Standard for Test Method of Mechanical Properties on Ordinary Concrete, Ministry of Housing and Urban-Rural Development of the People's Republic of China, Beijing, China, 2016.

[27] A. El-Zohairy, H. Salim, H. Shaaban, S. Mustafa, and A. ElShihy, "Experimental and FE parametric study on continuous steel-concrete composite beams strengthened with CFRP laminates," Construction and Building Materials, vol. 157, pp. 885-898, 2017.

[28] P. Desayi and S. Krishnan, "Equation for the stress-strain curve of concrete," ACI Journal Proceedings, vol. 61, no. 3, pp. 345-350, 1964.

[29] M. Bangash, Concrete and Concrete Structures: Numerical Modelling and Applications, Elsevier Applied Science, London, UK, 1989.

[30] A. M. El-Shihy, S. S. J. Moy, H. Shehab El-Din, H. F. Shaaban, and S. A. A. Mustafa, "Torsional effect on steel-concrete composite sections subjected to negative moment," Materials and Structures, vol. 45, no. 3, pp. 393-410, 2012. 


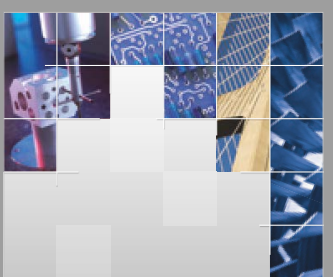

\section{Enfincering}
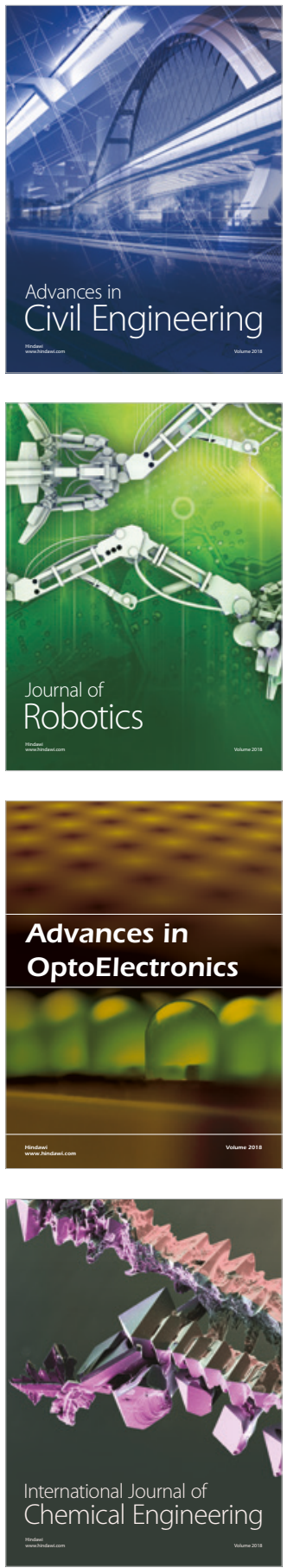

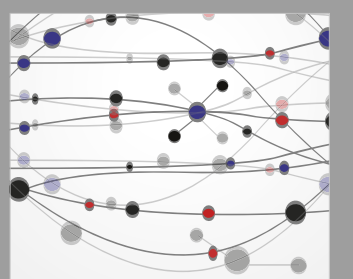

\section{Rotating \\ Machinery}

The Scientific World Journal

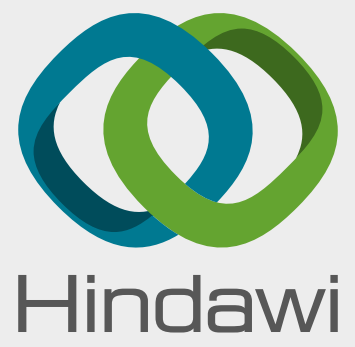

Submit your manuscripts at

www.hindawi.com
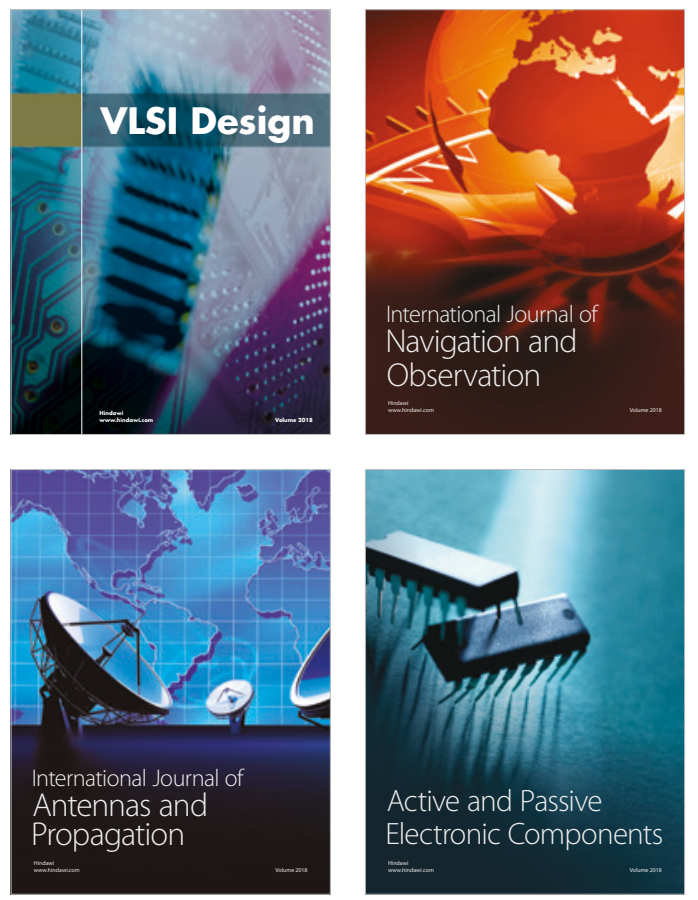
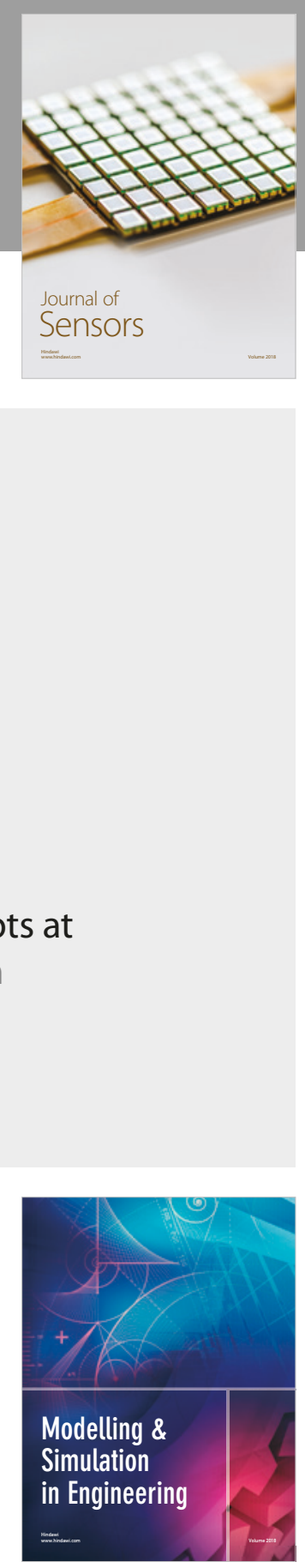

\section{Advances \\ Multimedia}
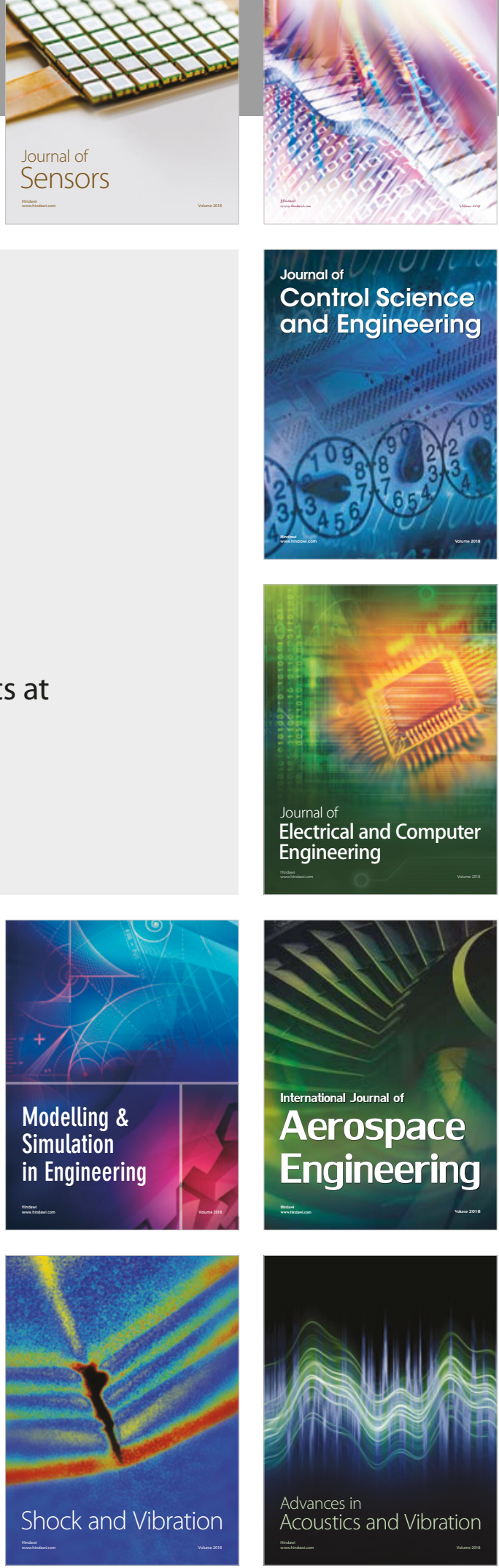